\title{
A review on the transmission of COVID-19 based on cough/sneeze/breath flows
}

\author{
Mouhammad El Hassan ${ }^{1, a}{ }^{\mathbb{D}}$, Hassan Assoum ${ }^{2}$, Nikolay Bukharin ${ }^{3}$, Huda Al Otaibi ${ }^{1}$, \\ Md Mofijur ${ }^{1,4}$, Anas Sakout ${ }^{5}$ \\ ${ }^{1}$ Mechanical Engineering Department, Prince Mohammad Bin Fahd University, Al Khobar, \\ Kingdom of Saudi Arabia \\ 2 Mechanical Engineering Department, Beirut Arab University, Tripoli, Lebanon \\ 3 School of Manufacturing and Automation, Southern Alberta Institute of Technology, Calgary, Canada \\ ${ }^{4}$ Faculty of Engineering and Information Technology, University of Technology Sydney, Sydney, NSW 2007, \\ Australia \\ 5 LASIE, University of La Rochelle, La Rochelle, France
}

Received: 5 July 2021 / Accepted: 8 November 2021

(C) The Author(s), under exclusive licence to Società Italiana di Fisica and Springer-Verlag GmbH Germany, part of Springer Nature 2021

\begin{abstract}
COVID-19 pandemic has recently had a dramatic impact on society. The understanding of the disease transmission is of high importance to limit its spread between humans. The spread of the virus in air strongly depends on the flow dynamics of the human airflows. It is, however, known that predicting the flow dynamics of the human airflows can be challenging due to different particles sizes and the turbulent aspect of the flow regime. It is thus recommended to present a deep analysis of different human airflows based on the existing experimental investigations. A validation of the existing numerical predictions of such flows would be of high interest to further develop the existing numerical model for different flow configurations. This paper presents a literature review of the experimental and numerical studies on human airflows, including sneezing, coughing and breathing. The dynamics of these airflows for different droplet sizes is discussed. The influence of other parameters, such as the viscosity and relative humidity, on the germs transmission is also presented. Finally, the efficacy of using a facemask in limiting the transmission of COVID-19 is investigated.
\end{abstract}

\section{Introduction}

At present, the world is suffering from the severe acute respiratory syndrome coronavirus disease (SARS-CoV-2) commonly known as COVID-19 which is an RNA virus that has a single strand and has similarity to SARS-CoV-1 in terms of evolutionary development and diversification $[67,112]$. This virus can cause lung inflammation, the main symptoms of COVID-19 patients are dry cough, fatigue, and fever [112]. In March 11th 2020, the WHO announced that COVID-19 became a pandemic. Healthcare infrastructure systems worldwide are overwhelmed due to the coronavirus pandemic because of its long incubation period and high contagiousness $[32,52]$. Current study shows that about $35 \%$ of infected persons do not exhibit overt symptoms [12] and this may unintentionally cause tremendous spread

\footnotetext{
a e-mail: melhassan@pmu.edu.sa (corresponding author)
} 
of the disease. The risk of acute infection containing virus greatly depends on the quality of the healthcare systems and physical factors of the infected persons [46]. COVID-19 is transmitted through the airborne droplets and aerosols that contains virus. Thus, the spread of respiratory droplets is a serious concern because of the fast transmission and spread of COVID-19 in people [108]. Therefore, studying the spread mechanisms, controlling strategies and prevention of COVID-19 has been a global concern to be solved.

For an infectious disease, it is important to consider the early transmission disease stages, which can help to control the disease transmission [81]. COVID-19 can be transmitted in three different routes that include emitted aerosol (airborne), contact transmission, and direct aerosol transmission [47]. Aerosol transmission means that droplets are mixed in the air and cause infection through inhalation process. It was shown in [92] that the SARS-CoV-2 virus might remain infectious as an aerosol for at least $3 \mathrm{~h}$. Contact transmission happens when there are droplets on the surface or objects that go inside the body through hands to mouth, nose, and eyes. Direct transmission means that there is a close contact with the droplets by coughing, sneezing and talking. One of the useful methods to demonstrate the transmission of diseases is the dynamical model, which simulates the mechanism of the virus transmission to predict future trends based on the current knowledge [47, 53, 80, 104]. There is still, however, little work that focused on the dynamic modeling transmission of COVID-19 [81]. For example, Lin et al. [55] demonstrated the transmission dynamics of COVID-19 and explained how the virus outbreak happened in Wuhan. Tang et al. [82] showed a study based on the estimations of the risk transmission of COVID-19 and presented the effectiveness of using control strategy by intensive tracing which followed by isolation and quarantine. Chen et al. [16] designed a mathematical model using Reservoir-People (RP) transmission network that showed that the transmissibility of COVID-19 was higher than the Middle East respiratory syndrome in the Middle East countries, similar to severe acute respiratory syndrome, but lower than MERS in the Republic of Korea.

Many researches (Gupta et al. [17], Wei and Li [18]) provided useful information to predict the spread of the disease from the flow that is generated by sneezing/coughing. Bourouiba et al. [10] conducted an experimental flow visualization to observe the expiratory flow from human using turbulent jets with liquid droplets for studying sneeze/cough dynamics. The use of direct numerical simulation (DNS) of the sneeze/cough events, which includes the phase-change thermodynamics and the small droplets dynamics, has not yet been reported [25].

This paper aims to provide a better understanding of the infectious diseases' transmission related to coughing, sneezing and breathing. Existing experimental and numerical investigations on human airflows and their impact on infectious disease transmission are presented. Finally, the effectiveness of wearing facemask in reducing the transmission of COVID-19 is discussed.

\section{Cumulus cloud flows and fluid fragmentation dynamics}

A better understanding of the transport process of viruses such as deadly influenza and COVID-19 is needed in order to minimize their spread. Infected patients can generate droplets by coughing, sneezing, or even breathing Bourouiba [9], Settles [73].

Cumulus cloud flow is of high importance to determine the trajectory and the spread rate of the droplets for a better understanding of the underlying turbulent flow. This cloud shows similarity to the atmospheric clouds [25]. Many authors studied theoretically, experimentally, and numerically the mechanisms involved in cloud flow which is a key mechanism in 
investigating the trajectory and the spread rate of the cough/sneeze flow and that has a strong similarity to atmospheric cloud [3, 26, 36, 61].

Diwan et al. [26] used Boussinesq equations in their numerical simulation to minimize latent heat released from cumulus clouds, they successfully reproduced cumulus clouds as shown in Fig. 1. In addition, Diwan et al. [25] developed equations containing a field of water liquid and water vapor (including thermodynamics of phase change) and a numerical code called "MEGHA-5" was developed by Ravichandran [65] which consisted of an MPIparallelized code known by its capability to scale to 4000 cores for solving the dynamical equations of cloud flows. They, however, faced some challenges in terms of sneeze/cough flows such as the inertia and the influence of phase change on droplets. They handled these problems in MEGHA-5 using two approaches. First, the liquid phase was treated as a field with suitable consideration for the droplet inertia for the dependence of evaporation on a specific distribution of droplet size and for the effect on the floating due to evaporative cooling. Second, they tracked each droplet and combined its dynamics to the flow equations. They also integrated a DNS code for studying cough/sneezing flow, the parameters that were recorded (duration: 200-500 ms) were the Reynolds number $\operatorname{Re}=11,318$, the ambient temperature $\mathrm{T}_{\mathrm{a}}=22{ }^{\circ} \mathrm{C}$, the cough fluid temperature $\mathrm{T}_{\mathrm{f}}=34{ }^{\circ} \mathrm{C}$ and the expelled volume between 0.25 and $1.6 \mathrm{~L}$. They focused on coughing problems that are relevant to COVID-19 using a cuboidal domain to simulate a room with suitable boundary conditions (Fig. 2a). There was also an orifice to eject the puff. The cough waveform can be seen in Fig. $2 \mathrm{~b}$ with a total cough duration of $0.53 \mathrm{~s}$. They included that the buoyancy effect because the cough fluid temperature is different from the ambient temperature. Figures $3 \mathrm{a}, \mathrm{b}$ show the temperature distribution for dry cough flow for two time instants $t=0.86 \mathrm{~s}$ and $9.37 \mathrm{~s}$, respectively. In this cough flow there is a rapid drop in the cough-fluid temperature and lateral spreading of the flow. The cough flow persists for longer time as compared to the total duration of the cough which can help as an input for epidemiological studies. The authors concluded that using DNS gives a much more accurate estimation of the droplet finish distance than RANS models. They showed that the cough flow could extend up to $1.4 \mathrm{~m}$ [25]. Their study can guide the development of mathematical models for safer separation distance to avoid COVID-19 infection.

Bourouiba et al. [8] visualized coughing and sneezing dynamics that was produced by an adult. Violent respiratory events were recorded using high-speed imaging at 1000-4000 frames per second (f.p.s). It was found that cough and sneeze consist of turbulent cloud droplets of buoyant gas. Smaller droplets were affected to varying degrees within the cloud of turbulent gas, while the largest droplets remained unaffected by the gas phase flow and they followed a ballistic trajectory. The authors compared the emitted large cough droplets with the air cloud path. The smoke cloud was directed downward at an angle of $24^{\circ} \pm 7^{\circ}$ that is close to the mouth exit angle. The mouth opening area was equal to $3.4 \mathrm{~cm}^{2}$ and the trajectory length equals to $70 \mathrm{~cm}$, which shows an agreement with previous studies such as Gupta et al. [38]. In their flow visualizations, sneezes cloud appeared to be denser than the cough cloud. Moreover, the sneeze cloud was observed to be shorter than cough cloud for the same individual because small droplets are capable to move faster and for a long distance, the observed duration was $200 \mathrm{~ms}$. Reynold number that was used in this simulation for coughing and sneezing was equal to $10^{4}$ and $4 \times 10^{4}$, respectively, based on the observed ejection geometry and speed using high-speed camera. Finally, Bourouiba et al. [8] presented the circulation of sneezing clouds based on the change of arrows orientation, which illustrated the buoyancy influence in deflecting the cloud upward. A better illustration of the evolution of sneeze and cough cloud emitted horizontally was presented. These experimental results can be used with the clinical data to improve the estimation of airborne disease transmission. 

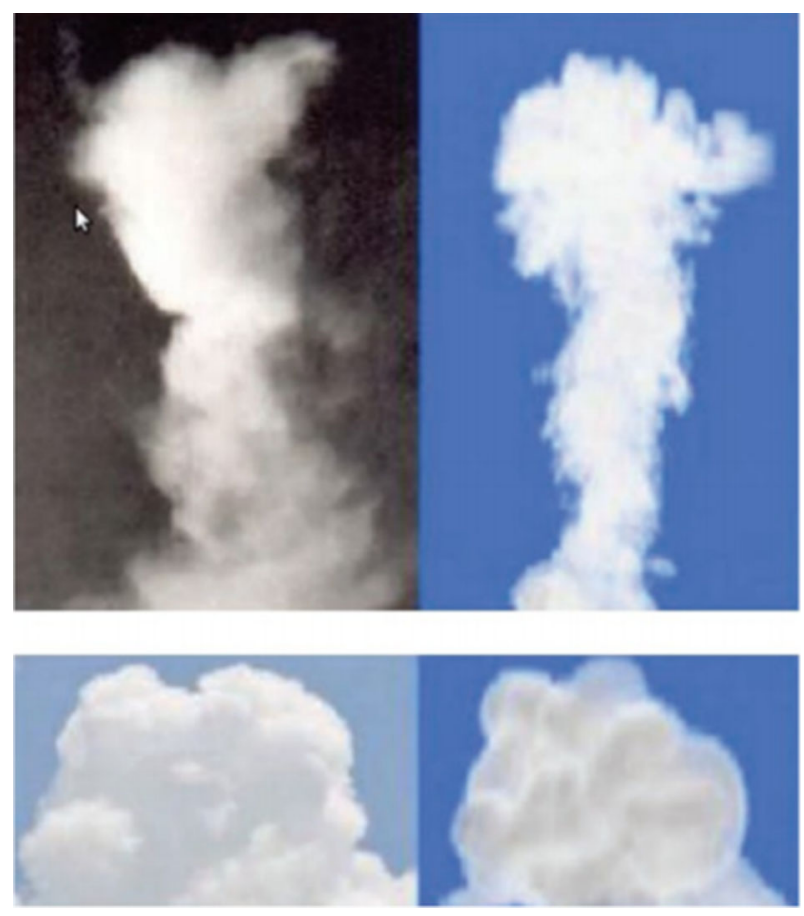

Fig. 1 Comparison of natural clouds (left) with cumulus clouds (right) [26]

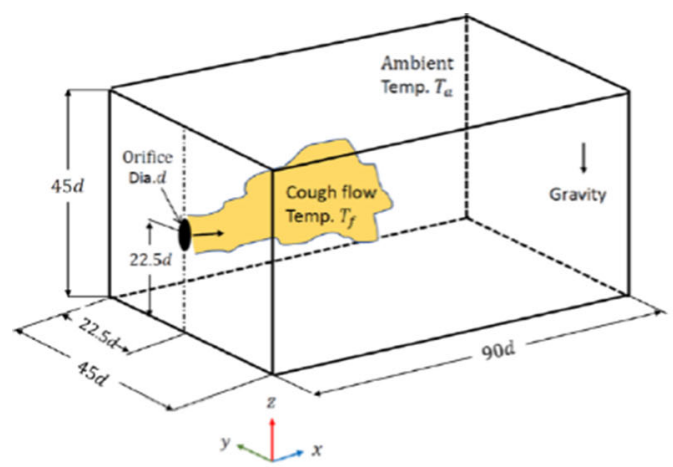

(a)

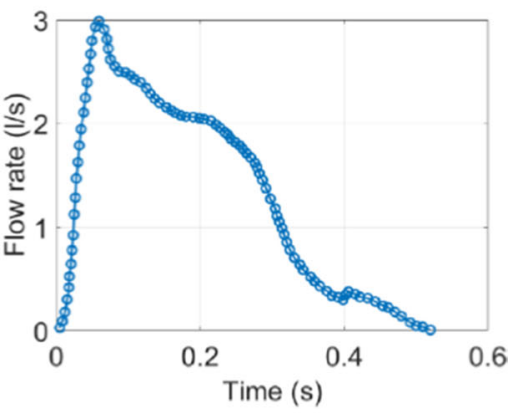

(b)

Fig. 2 a Computational domain schematic. b Flow rate variation during a single cough event [25]

Observations show that sneezes and coughs can produce ejecta which is how the droplets of coughs and sneezes mixed with an ambient air that is described as a turbulent multiphase cloud of moist air [8].

Some recent studies focused on talking, coughing, and respiration based on the drop size measurement [60, 69, 105]. As early as, Turner et al. [89] recorded sneezes by using dark-field imaging set up with flash photographs and highlighted major parts of the emission process. Duguid (1946) studied sneezing dynamics in detail. However, most studies examined 


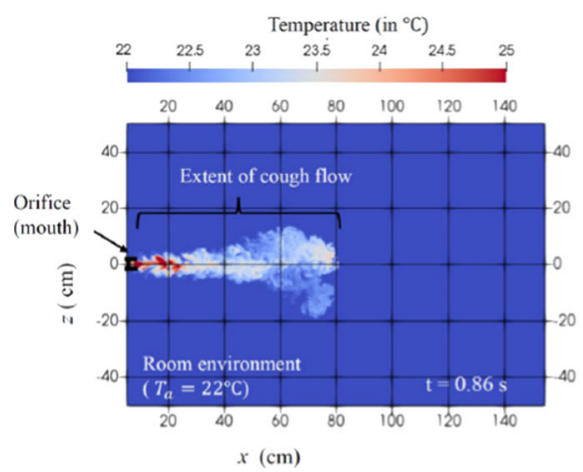

(a)

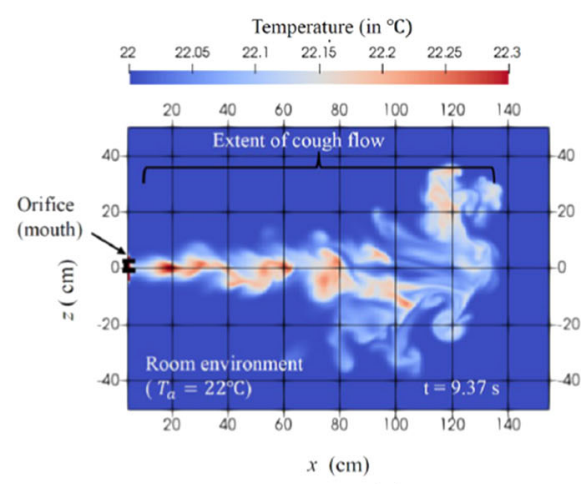

(b)

Fig. 3 Simulation of "dry cough": temperature distribution at two time instants a at $0.86 \mathrm{~s}, \mathbf{b} 9.37 \mathrm{~s}$ [25]

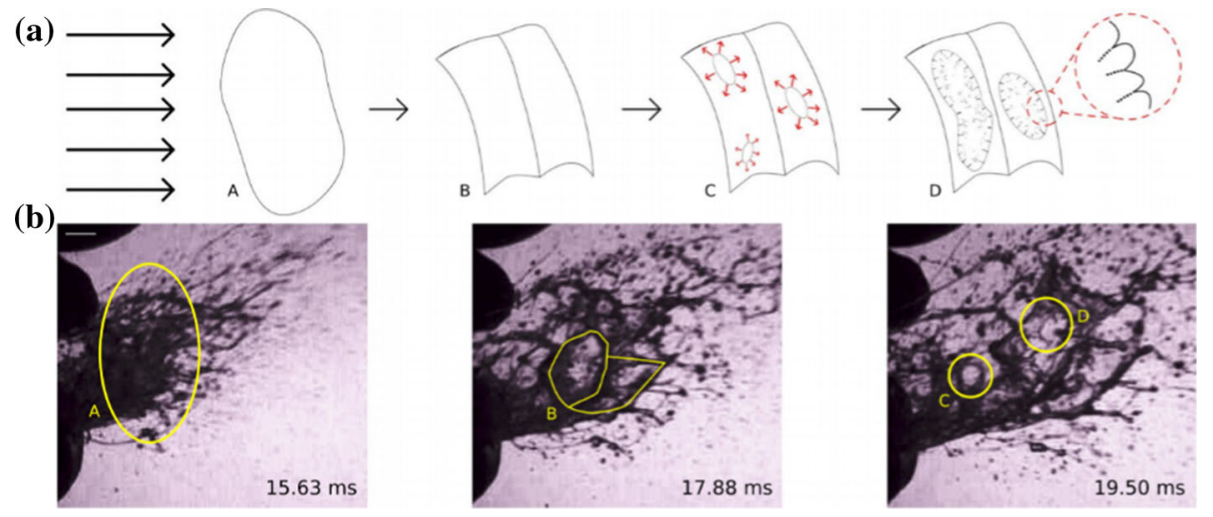

Fig. 4 a Fragmentation process schematic of a liquid in response to aerodynamic forces, $\mathbf{b}$ photograph of sneeze ejecta $[70,74]$

sneeze dynamics by using dyed solutions which ingested by the subject and directed to a celluloid-surfaced slide for flow visualization and sneeze dynamics examination.

It was also found that fluid viscosity and surface tension mostly in favor of large droplets, while higher air speeds appear to produce in smaller droplets [70, 74]. In addition, saliva physical properties are close to those of water with density of $\rho=1000 \mathrm{~kg} / \mathrm{m}^{3}$, surface tension of $\sigma=60 \mathrm{~N} / \mathrm{m}$ and dynamic viscosity $\mu=1$ Pa.s Schipper et al. [71], Stokes and Davies [78]. These fluids contain agents such as proteins, salts, and fatty acids [4]. They also are viscoelastic due to the dissolved biopolymers and large glycoprotein mucins [24]. Moreover, many studies provide a detailed analysis of the fluid partial bubbles which known as fluid bag dynamics which is another feature of fluid breakup that happens in a variety of liquid-gas flows [93]. Fluid bag typically consists of a liquid volume, which when subjected to a net air flow in a specific direction, deforms by aerodynamic pressure that tends to flatten the liquid volume into a sheet that extends as it is swept downstream as seen in Fig. 4 [70, 74]. Then the flattened bag structure expands and thins until the bag becomes unstable and ruptures.

Scharfman et al. [70, 74] used high-speed visualizations of cough and sneeze (1000-8000 f.p.s) as shown in Fig. 5. The subject head was positioned in front of a black felt backdrop to create a dark domain effect. This approach allows the droplets to disturb the light toward 
Fig. 5 Experimental setup schematic that used to record sneezes image [70, 74]

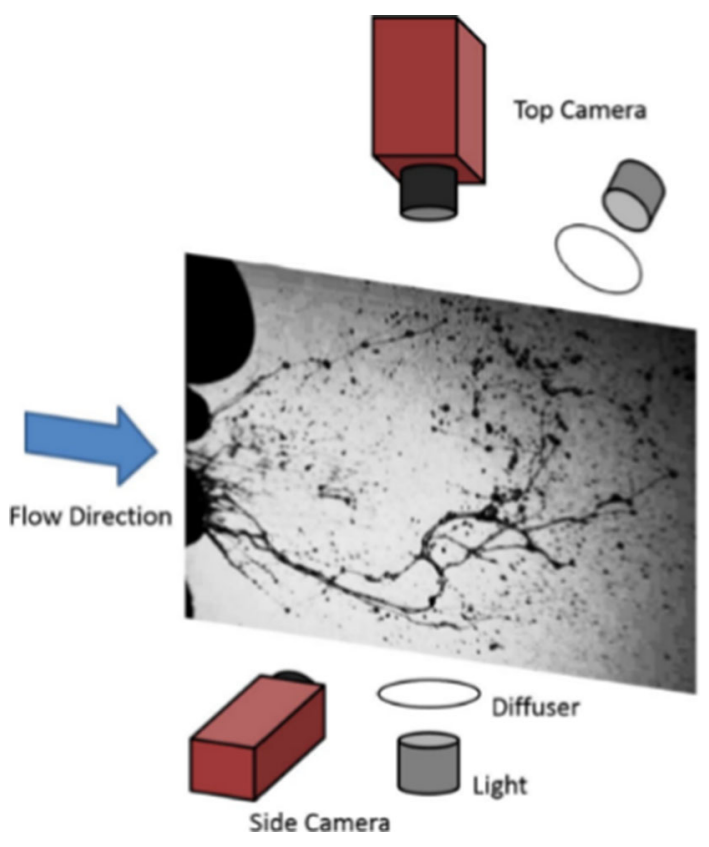

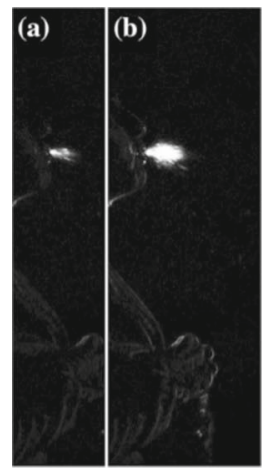
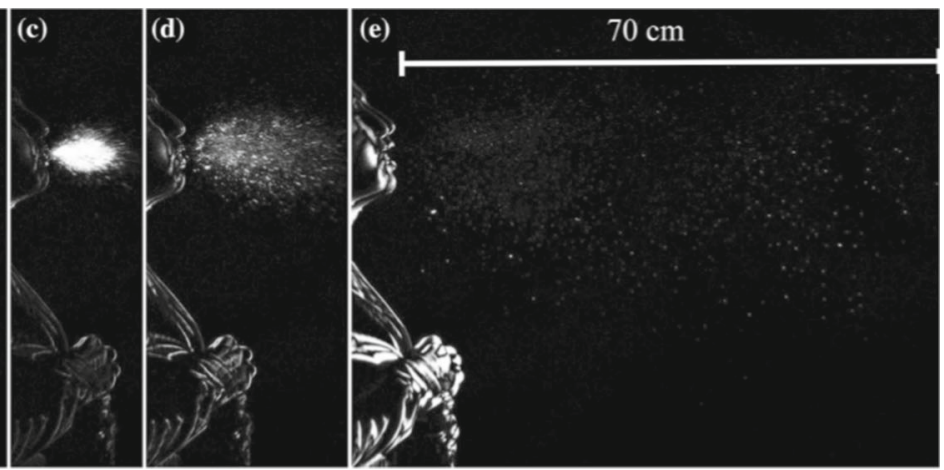

Fig. 6 High-speed imaging of cough recording at 1000 f.p.s at a 0.005 s, b 0.008 s, c 0.015 s, d 0.032 s, e 0.15 s. $[70,74]$

the cameras as seen in Fig. 6, which leads to enhanced contrast. This setup was insightful for far-field visualization of sneezes cloud dynamics since two cameras were used simultaneously to record the fluid fragmentation. Their findings showed the shortcoming of the recent belief that the droplets of the respiration process are formed before the ejection. The authors showed how the viscoelasticity plays a major role in the final size distribution [70, 74]. However, a theoretical and experimental framework for studying the effect of viscoelasticity on fragmentation to predict the final droplet size is still under development. Fragmentation process in determining the final droplet size should also be investigated to evaluate the risk of violent expiration. A summary of the objectives and findings on cumulus cloud and droplet dynamics is shown in Table 1. 
Table 1 Summary of the objectives and findings on cumulus cloud and droplet dynamics

\begin{tabular}{|c|c|c|}
\hline Paper & Objective & Method and results \\
\hline Diwan et al. [25] & $\begin{array}{l}\text { The objective was to understand the } \\
\text { transmission dynamics of COVID-19 } \\
\text { by investigating the fluid dynamics of } \\
\text { sneezing and coughing }\end{array}$ & $\begin{array}{l}\text { Developed the MEGHA- } 5 \text { code to } \\
\text { accurately study the thermodynamics } \\
\text { of phase change for different droplet } \\
\text { sizes }\end{array}$ \\
\hline Diwan et al. [26] & $\begin{array}{l}\text { The objective was to describe the } \\
\text { adiabatic transient flow in order to } \\
\text { simulate the cumulus cloud during its } \\
\text { life cycle }\end{array}$ & $\begin{array}{l}\text { Their approach separates the } \\
\text { thermodynamics of phase change of } \\
\text { cumulus cloud from the flow } \\
\text { dynamics by treating the latent heat, } \\
\text { released in the cloud, as a heat } \\
\text { injection in a transient plume. A } \\
\text { correlation between the temperature } \\
\text { gradients in the flow and the velocity } \\
\text { provided important information about } \\
\text { the fluid dynamics }\end{array}$ \\
\hline Bourouiba et al. [8] & $\begin{array}{l}\text { The objective was to combine } \\
\text { theoretical and experimental } \\
\text { investigation of flow dynamics in } \\
\text { violent expiratory events }\end{array}$ & $\begin{array}{l}\text { Their observations help in predicting } \\
\text { the range of pathogen transmissions } \\
\text { based on the droplets that remain in } \\
\text { the cloud until their speed matches the } \\
\text { decelerating cloud }\end{array}$ \\
\hline Gupta et al. [38] & $\begin{array}{l}\text { The objective was to develop a set of } \\
\text { simple equations that can be used as } \\
\text { boundary conditions for predicting } \\
\text { virus transport in CFD simulations }\end{array}$ & $\begin{array}{l}\text { Their work focused on the flow } \\
\text { direction, flow rate and velocity of the } \\
\text { air that can be determined from mouth } \\
\text { opening area and flow rate. The } \\
\text { variation in the flow rate of coughing } \\
\text { with time can be represented as } \\
\text { gamma-probability-distribution } \\
\text { functions }\end{array}$ \\
\hline
\end{tabular}

\section{Experimental investigations of human airflows (coughing, sneezing and breathing)}

Studying the flow dynamics of human airflows is very crucial in order to understand the spread of the ejected particles during coughing, sneezing or breathing. This allows to understand the transmission mechanism of infections via expelled contaminants, which is very essential when we are seeking to establish a safe indoor environment such as in airplanes, residential buildings or other enclosed areas.

The time for which ejected droplets in a human airflow can stay airborne is decisive for the infection transmissions. This is dependent on the droplets' size and number [27]. These particles cannot remain airborne long when they are larger than $100 \mu \mathrm{m}$ in diameter, i.e., 1 or $2 \mathrm{~s}$ before settling to the ground, whereas smaller particles would evaporate before they drop to the ground and stay airborne for multiple days as it was reported by [99] who was the first to challenge this view and was the first to study the transmission of respiratory disease via airborne droplets.

In this section, a literature review of the experimental fluid dynamic studies of coughing, sneezing and breathing mechanisms is presented. 
Fig. 7 A subject with a mask holding the spirometer during test [38]

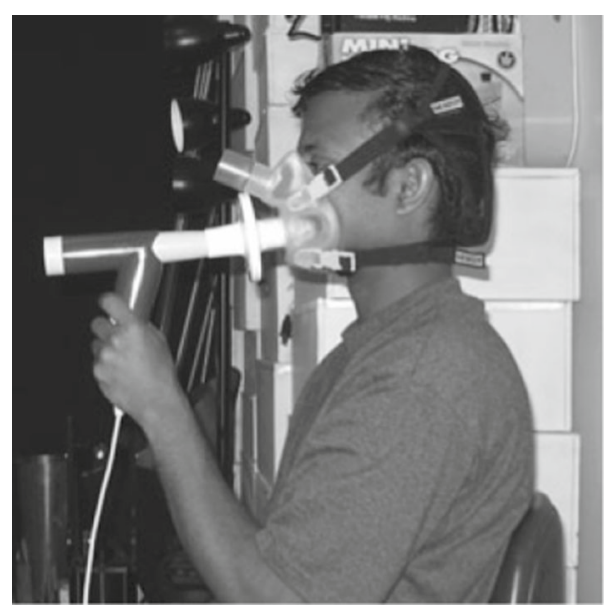

\subsection{Coughing}

Several studies investigated coughing with human subjects using particular image velocimetry (PIV) or other experimental methods [27, 103, 111, 38].

In order to measure the number and size of particles produced by a healthy person throughout talking and coughing, Xie et al. [103] employed a Microscope glass slides and watersensitive paper (WSP). The average droplets' size was found to be about 50-100 $\mu \mathrm{m}$. Duguid [27] introduced a dye powder called eosin to the surface of the mouth and the tongue of volunteers. Different types of human airflows were produced by sneezing, coughing or speaking in the face of a celluloid sheet. A micrometer eyepiece was used to measure the size of the first hundred droplet-marks met on the impinging sheet. For each type of expiratory activity, 10 to 22 tests were done and which involved the measurement of 3000 droplets. It was found that the diameters of droplets produced in sneezing, coughing or speaking ranged essentially from 2 to $100 \mu \mathrm{m}$. Gupta et al. [38] used a spirometer consisting of capillary tubes (Fig. 7) to measure the pressure drop which is, according to Poiseuille's law, proportional to the flow rate. They used a low speed photography with a frequency of $120 \mathrm{~Hz}$ to visualize the direction of the flow seeded by cigarette smoke (Particle size $=0.2^{-} \mathrm{m}$ ). Flow rate, flow direction, and mouth opening area were considered for 25 volunteers. It was shown that two single coughs can represent the behaviour of a sequential cough. The visualized flow was found to not vary a lot with subjects and they proposed to use a mean mouth opening area for such human flows.

Zhu et al. [111] used Particle Image Velocimetry (PIV) to measure the cough velocity from three male subjects. Their results showed that the initial velocity had an average equal to $11.2 \mathrm{~m} / \mathrm{s}$ ranging from 6 to $22 \mathrm{~m} / \mathrm{s}$ with a standard deviation of $2.85 \mathrm{~m} / \mathrm{s}$. Chao et al. [13] used PIV and Interferometric Mie Imaging (IMI) data to record 11 subjects during speaking and coughing; saline fog was used as tracer. The average velocity of 50 coughs from each patient was $11.7 \mathrm{~m} / \mathrm{s}$ (with a droplet size equal to $13.5^{-} \mathrm{m}$ ) and $3.9 \mathrm{~m} / \mathrm{s}$ for speaking (with a droplet size equal to $16 \mu \mathrm{m}$ ). The IMI optical technique is employed to measure the droplet size; more details about this experimental method can be found in Glantschnig and Chen [34], Glover et al. [35].

Relationship of Cough Peak Flow Rate (CPFR) and Peak Velocity Time (PVT) in coughing was the purpose of several studies (Mahajan et al. [58], Singh et al. [77] where the authors 


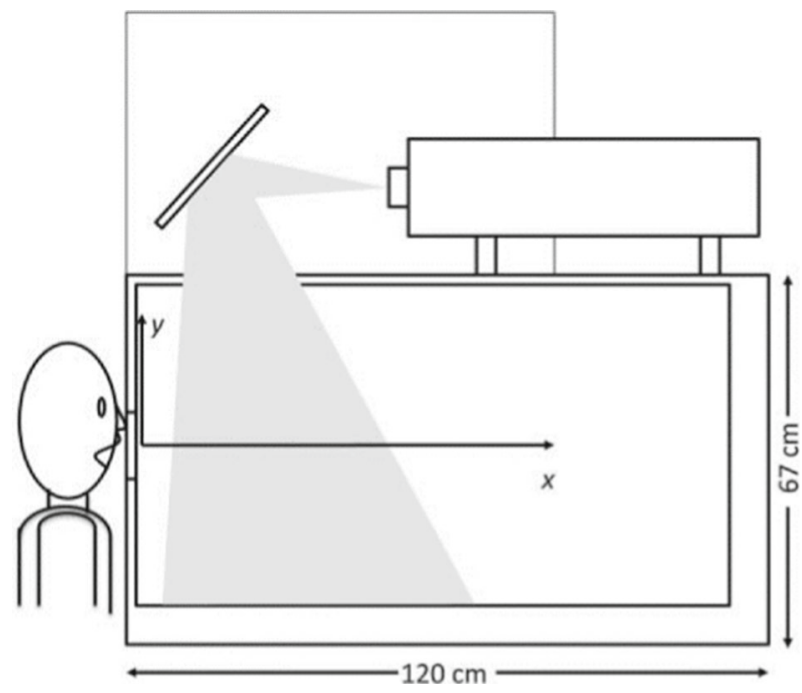

Fig. 8 PIV Setup (VanSciver et al. 2011)

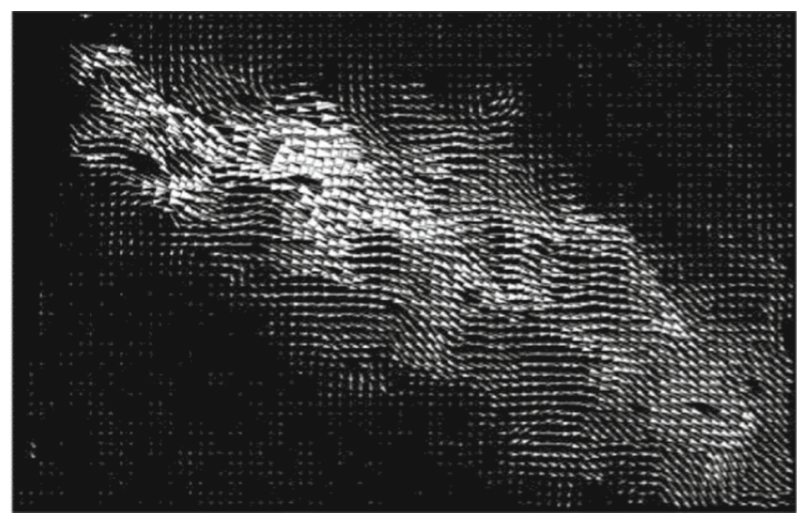

Fig. 9 PIV of Cough flow (VanSciver et al. 2011)

used a pneumotachograph (tusso-meter) to measure the airflow. Mahajan et al. [58] measured CPFR from $200 \mathrm{~L} / \mathrm{min}$ to $950 \mathrm{~L} / \mathrm{min}$ with a mean peak flow rate of $300 \mathrm{~L} / \mathrm{min}$ with a delay ranging from 15 to $40 \mathrm{~ms}$ before reaching these flow rates. Singh et al. [77] measured CPFR of $750 \mathrm{~L} / \mathrm{min}$ and $1300 \mathrm{~L} / \mathrm{m}$ for women and men, respectively. Kwon et al. [50] measured an average initial velocity of $15.3 \mathrm{~m} / \mathrm{s}$ and $10.6 \mathrm{~m} / \mathrm{s}$ for males and females, respectively. Moreover, VanSciver et al. [91] used PIV measurements to investigate the flow dynamics involved in a cough from twenty-nine non-smoking volunteers inside an enclosure of $67 \mathrm{~cm}$ in height, $76 \mathrm{~cm}$ in width, and $120 \mathrm{~cm}$ in length (Fig. 8). The average maximum velocity ranged from 1.15 to $28.8 \mathrm{~m} / \mathrm{s}$ for all volunteers, and the corresponding Reynolds number ranged from 2300 to 57,600 . The average of overall maximum coughing velocity was $10.2 \mathrm{~m} / \mathrm{s}$. Figure 9 shows a cough velocity field obtained from the PIV measurements [91].

Wei and Li [98, 102] studied human cough and characterized it as a two-stage jet; the first is the starting one (once the cough starts) and the second is an interrupted jet (when 


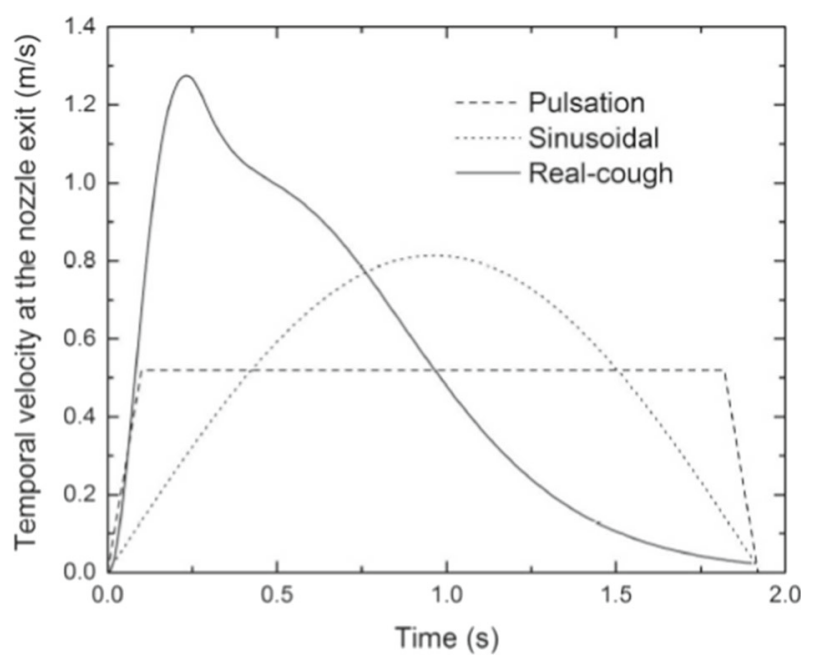

Fig. 10 Three temporal profiles at the nozzle exit $[98,102]$

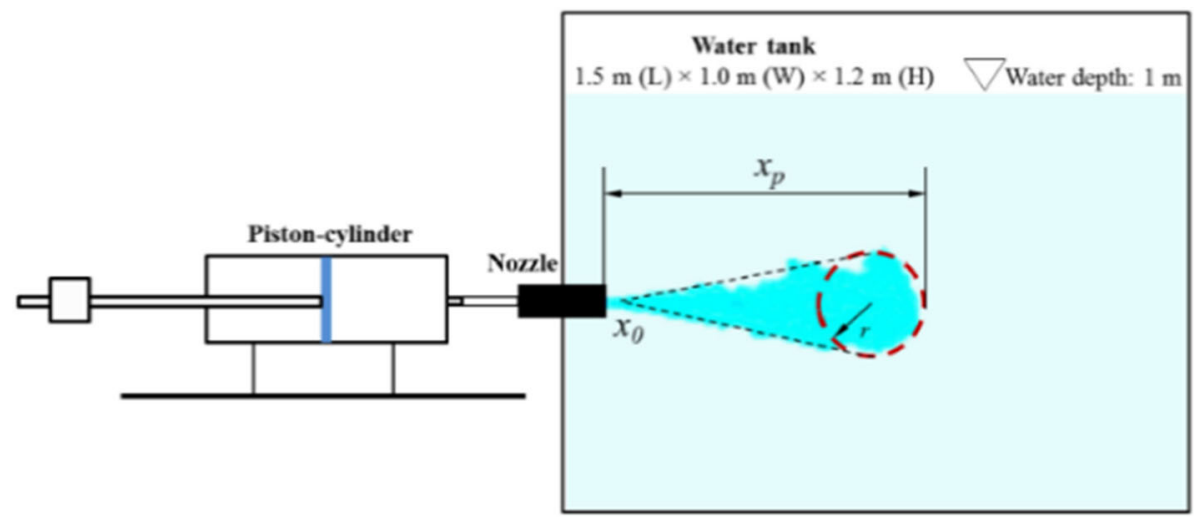

Fig. 11 Schematic diagram of the test apparatus $[98,102]$

the source is stopped). They employed the PIV technique and tested different boundary conditions at the exit of the jet created by a piston-cylinder facility (temporal velocity profile at the exit is shown in Fig. 10) in order to track the spread of expelled droplets. They conducted these experiments in water at $0.5 \mathrm{~m}$ in depth where a converging nozzle, with a uniform mean velocity profile at its exit, creates a jet at the middle of a $1.5 \mathrm{~m}$ (length) $\times 1 \mathrm{~m}$ (Width) $\times 1.2 \mathrm{~m}$ (height) rectangular tank. Two jet diameters were tested $(\mathrm{D}=4 \mathrm{~mm}$ and $\mathrm{D}=10 \mathrm{~mm})$. They used glass particles of three sizes for the tracers: small $(30-50 \mu \mathrm{m})$, medium $(210-250 \mu \mathrm{m})$ and large $(355-420 \mu \mathrm{m})$, respectively. The jet was created using a piston-cylinder system (Fig. 11).

For all cases, it was found that the temporal exit velocity profiles had negligible effect on the stream distance penetration $(50.6-85.5 \mathrm{D}$, range where $\mathrm{D}=2 \mathrm{~cm}$ is the diameter of the nozzle) Wei and Li [98, 102]. For the three categories of particles (small, medium and large), no clear difference was found in their streaks before the supply of the jet is stopped (Fig. 12a). When $\mathrm{t}=10^{*} t_{\text {inj }}$ (Fig. 12b, where ' $t_{i n j}=0.5 \mathrm{~s}$ ' is the cough duration), the cloud 

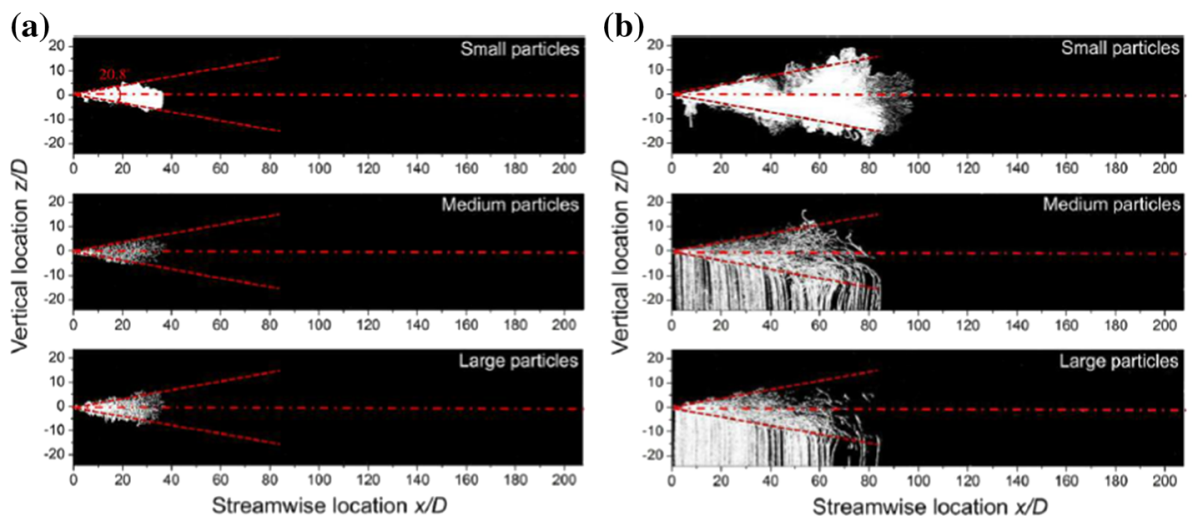

Fig. 12 Streak pictures of particles (Pulsation, $\mathrm{Re}=12,900)$. The red dashed line indicates the jet boundary. The pictures overlap from $t=0$ to $(A)$ the time when the jet is interrupted $\left(t=t_{\text {inj }}\right)$, and (B) $t=10 t_{\text {inj }}[98$, 102]

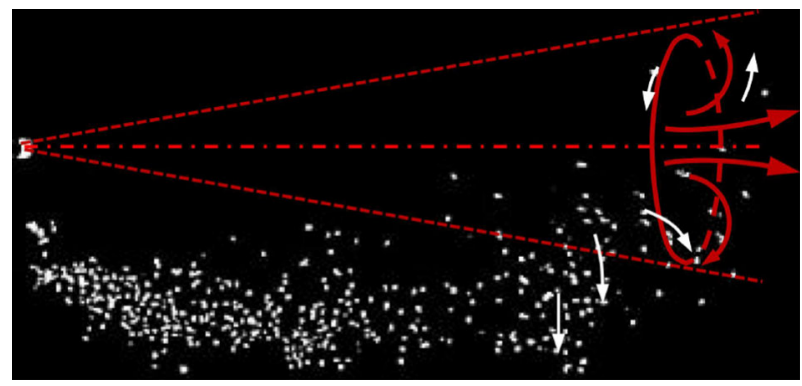

Fig. 13 The leading vortex is illustrated by red arrows, and white arrows indicate the particle motion [98, 102]

of particles reach a maximum distance of $80 \mathrm{D}$. In contradictions with previous studies (e.g., Xie et al. [103], medium and small particles had similar maximum travel distance. This was explained by the leading vortex who strengthen the droplets' spread as illustrated in Fig. 13. Actually, the upper leading vortex provides a positive vertical velocity which carry the particles upward.

Other experimental investigations have combined different metrologies to study human airflows. For example, Zhang et al. (2019) established experimental measurements in order to validate CFD models. They used a thermal manikin heated uniformly by a resistance wire that allowed having a temperature around $30{ }^{\circ} \mathrm{C}$ on most of the manikin surface as for a human body. Droplets were generated by a specific setup and their diameter ranged from 0.1 to $10 \mu \mathrm{m}$. These droplets were ejected from the nose of the manikin with an average velocity of $2.2 \mathrm{~m} / \mathrm{s}$. The aerosols concentration was then monitored at 3 points as shown in Fig. 14. The result of this study remains in studying the influence of different systems of ventilation on spreading droplets aerosols in enclosed areas.

Dudalski et al. [28] employed a PIV system consisting of CCD camera at a frequency of $15 \mathrm{~Hz}$ and a 532-nm Nd:YAG laser, providing $120 \mathrm{~mJ}$ per pulse in order to illuminate the seeded particles for studying the far-field human cough. They also used a Hot-Wire Anemometry HWA (at $1 \mathrm{kHz}$ ) to measure the velocity as function of time in a specific location. At the jet center, an average peak velocity of $1.2 \mathrm{~m} / \mathrm{s}$ was obtained and an average jet spread 
Fig. 14 Thermal manikin and test points (Zhang et al. 2019)

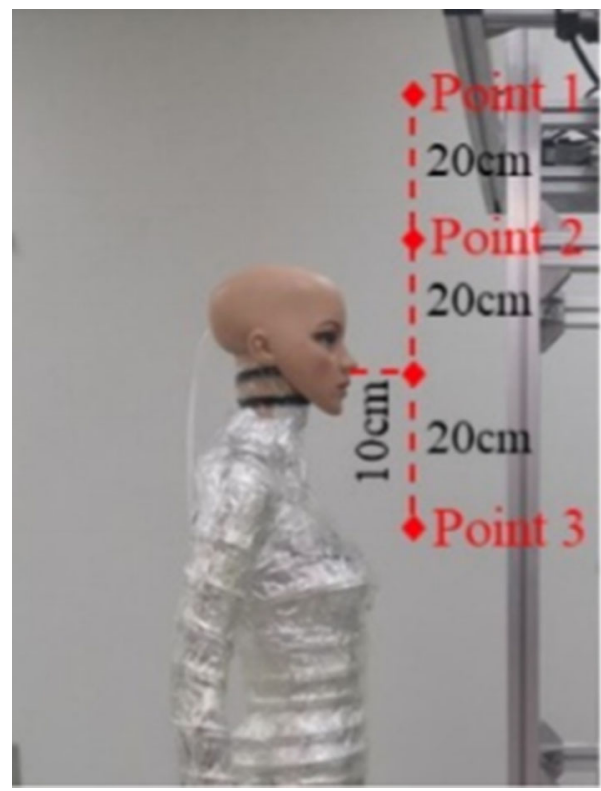

angle of $\theta=24^{\circ}$ was measured. No significant difference was detected between coughs from sick or healthy volunteers. These experimental data were used to validate computational fluid dynamics (CFD) models and a complete model was developed for the decay of centerline peak velocity.

\subsection{Sneezing}

Investigating flow dynamics of sneezing is more challenging than coughing since the sneezing reflex is difficult to induce for experimental purposes Tang et al. [83]. Jennison and Edgerton [44] employed photography strobe lighting and high-speed camera. They found sneeze velocities at about $30 \mathrm{~m} / \mathrm{s}$. They captured about 4600 expelled droplets using a camera with an $\mathrm{f} 11$ aperture and an exposure time of $6.6 \mathrm{~s}$. The range of apparent diameter of the droplets has been determined from photographic enlargements to be $0.1-2 \mathrm{~mm}$.

Other study on sneezing showed that the peak expiratory airflow during sneezing was 6-7 times higher than normal breathing [43]. Wells [101] studied sneezing flow and assumed that sneezing velocity can reach up to $100 \mathrm{~m} / \mathrm{s}$. Tang et al. [84] employed Schlieren imaging technique (Fig. 15) based on refraction of light through a medium of different densities, which is the case in a human airflow. The surrounding air temperature is about $25^{\circ} \mathrm{C}$ and the human airflow temperature is about $30^{\circ} \mathrm{C}$. In this experiment, a large astronomical telescope, having a $1 \mathrm{~m}$ diameter and a focal length of $5 \mathrm{~m}$, was used. They tested the efficacy of different ways of interventions (such as tissues across the mouth and nose) to decrease the transmission of airborne infection. The use of a 4-ply tissue showed a high efficiency and proved that making such intervention to contain one's sneeze puffs is beneficial.

Tang et al. [83] employed the same Schlieren imaging system as in [84] to track the flow dynamics involved in a cough produced by a healthy person (Fig. 16). This methodology has its limitation because of its dependence on relative changes in densities between the human air flow and the ambient air. Actually the air leaving the human mouth, quickly cools 
spherical

mirror

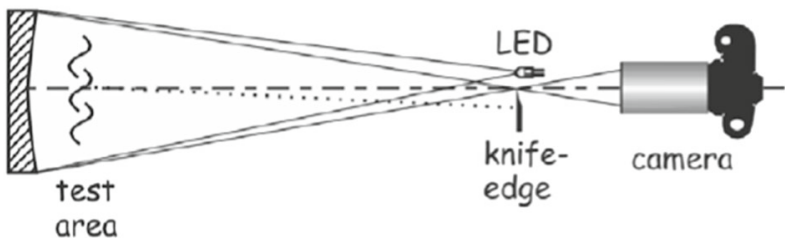

Fig. 15 Schematic of Schlieren optical imaging system set-up [84]

Fig. 16 Digitized shadowgraph image of a human volunteer coughing [83]

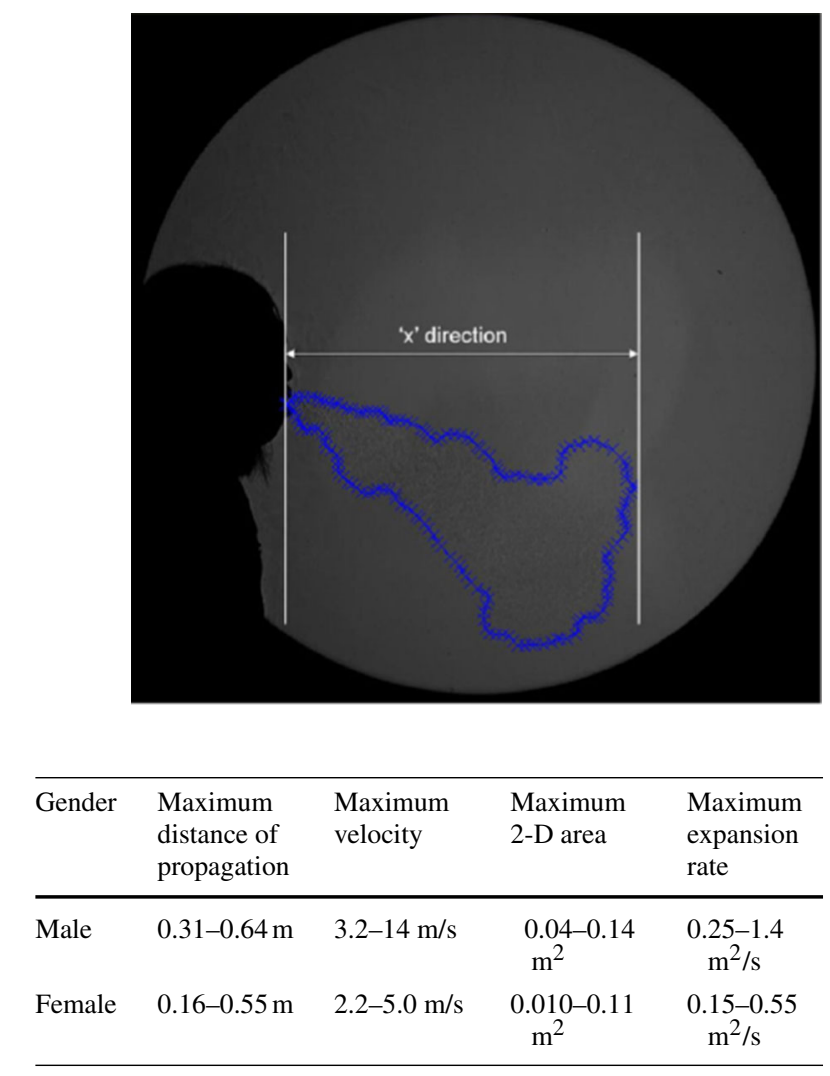

\begin{tabular}{lllll}
\hline Gender & $\begin{array}{l}\text { Maximum } \\
\text { distance of } \\
\text { propagation }\end{array}$ & $\begin{array}{l}\text { Maximum } \\
\text { velocity }\end{array}$ & $\begin{array}{l}\text { Maximum } \\
\text { 2-D area }\end{array}$ & $\begin{array}{l}\text { Maximum } \\
\text { expansion } \\
\text { rate }\end{array}$ \\
\hline Male & $0.31-0.64 \mathrm{~m}$ & $3.2-14 \mathrm{~m} / \mathrm{s}$ & $\begin{array}{c}0.04-0.14 \\
\mathrm{~m}^{2}\end{array}$ & $\begin{array}{c}0.25-1.4 \\
\mathrm{~m}^{2} / \mathrm{s}\end{array}$ \\
Female & $0.16-0.55 \mathrm{~m}$ & $2.2-5.0 \mathrm{~m} / \mathrm{s}$ & $\begin{array}{c}0.010-0.11 \\
\mathrm{~m}^{2}\end{array}$ & $\begin{array}{c}0.15-0.55 \\
\mathrm{~m}^{2} / \mathrm{s}\end{array}$ \\
\hline
\end{tabular}

Table 2 Spread distances, velocities areas and expansion rates of cough [83]

because of the colder surrounding volume of air what limits the visibility of this moving human airflow. However, it does not use irritant or toxic particles to track the fluid dynamics and does not employ high power of lighting, as it is the case in the PIV technique. In this study, twenty healthy volunteers were tested (10 males, 10 females). The maximum spread distances, velocities and $2 \mathrm{D}$ projected areas are summarized in Table 2.

Bahl et al. [5] used a halogen spotlight and a High-speed monochrome camera to track individual droplets ejected through a sneeze (Fig. 17). Flow fields of multiple sneezes showed that less than $1 \%$ of expelled droplets had velocities greater than $10 \mathrm{~m} / \mathrm{s}$ while $80 \%$ of droplets had velocities less than $5 \mathrm{~m} / \mathrm{s}$. They also noticed the effect of the viscoelasticity of exhaled 

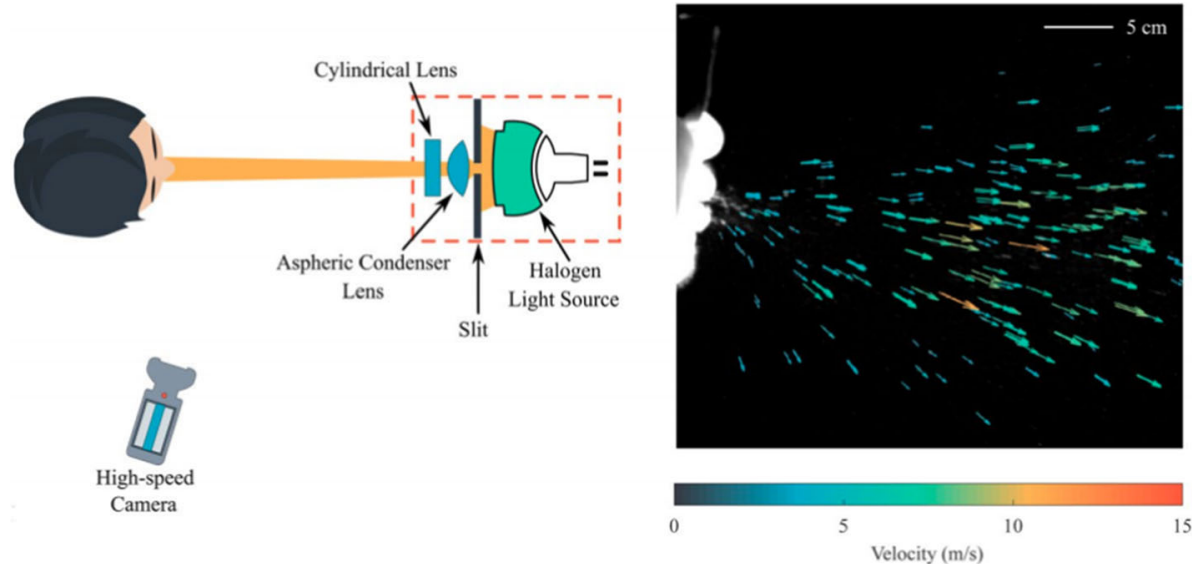

Fig. 17 Experimental setup used to capture droplets expelled during a sneeze (Bahl et al. 2020)

droplets from different humans in determining the size distribution of large droplets and the extent of their spread.

\subsection{Breathing}

It is of high importance to examine human breathing flow, which is known to produce slow moving flows than sneezing and coughing. However, there are only few studies that focus on breathing flow dynamics. Tang et al. [85] found that the maximum cough and sneeze velocities are similar. The airflow profiles for nasal and mouth breathing were found to be similar and differ only in their relative direction, they have similar spreading distances and velocities. These authors measured a maximum penetration distance of $0.6 \mathrm{~m}$ and $0.8 \mathrm{~m}$, a 2-D area of spreading of $0.11 \mathrm{~m}^{2}$ and $0.18 \mathrm{~m}^{2}$ and an expansion rate of $0.16 \mathrm{~m}^{2} / \mathrm{s}$ and $0.17 \mathrm{~m}^{2} / \mathrm{s}$ for nasal and mouth breathing, respectively. Gupta et al. [39] performed many experiments and numerical simulations to examine the flow dynamics from nose and mouth breathing. They found that exhaled flow rate can be described by a sinusoidal function over time for breathing. Body height, weight, and gender of each volunteer determine the amplitude and frequency of this function. They defined the direction of the exhaled jet by two front angles and two sideangles and only one side-angle during breathing from nose and mouth, respectively. Feng et al. [33] conducted a 2D time-resolved PIV investigation on human exhalation flow. They used a breathing manikin (Fig. 18) and applied the phase-average method on the kinematic fields since the studied phenomenon was periodic. The entire process of breathing was described with quantitative data what could be used for validation of numerical simulations.

Papineni and Rosenthal [64] measured exhaled droplets from breathing by an optical particle counter (OPC) and an analytical transmission electron microscope (AEM). The OPC showed a majority of droplets less than $1 \mu \mathrm{m}$. Measurements using the AEM technique indicated the presence of bigger droplets in the breath flow. Milton et al. [59] considered the effectiveness of facemasks as a means to reduce transmission of airborne infection. Surgical masks were confirmed to be reducing the spread of virus. Two particle size ranges were measured for exhaled influenza: $\geq 5 \mu m$ (coarse) and $<5 \mu m$ (fine). Overall, they found that masks are able to reduce the number of viral RNA by 3.4 fold.

Different experimental flow dynamic investigations on human airflows are summarized in Table 3. 


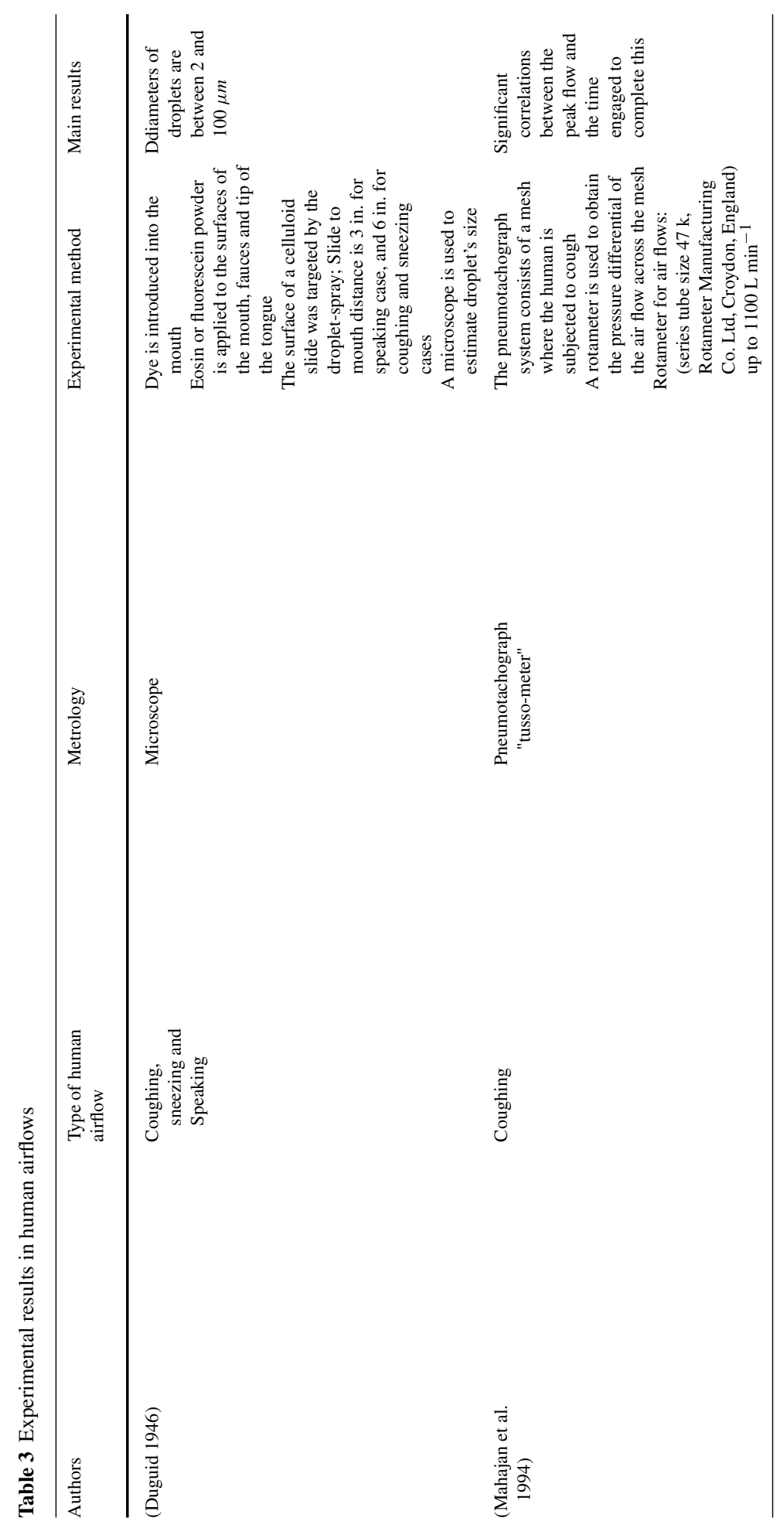




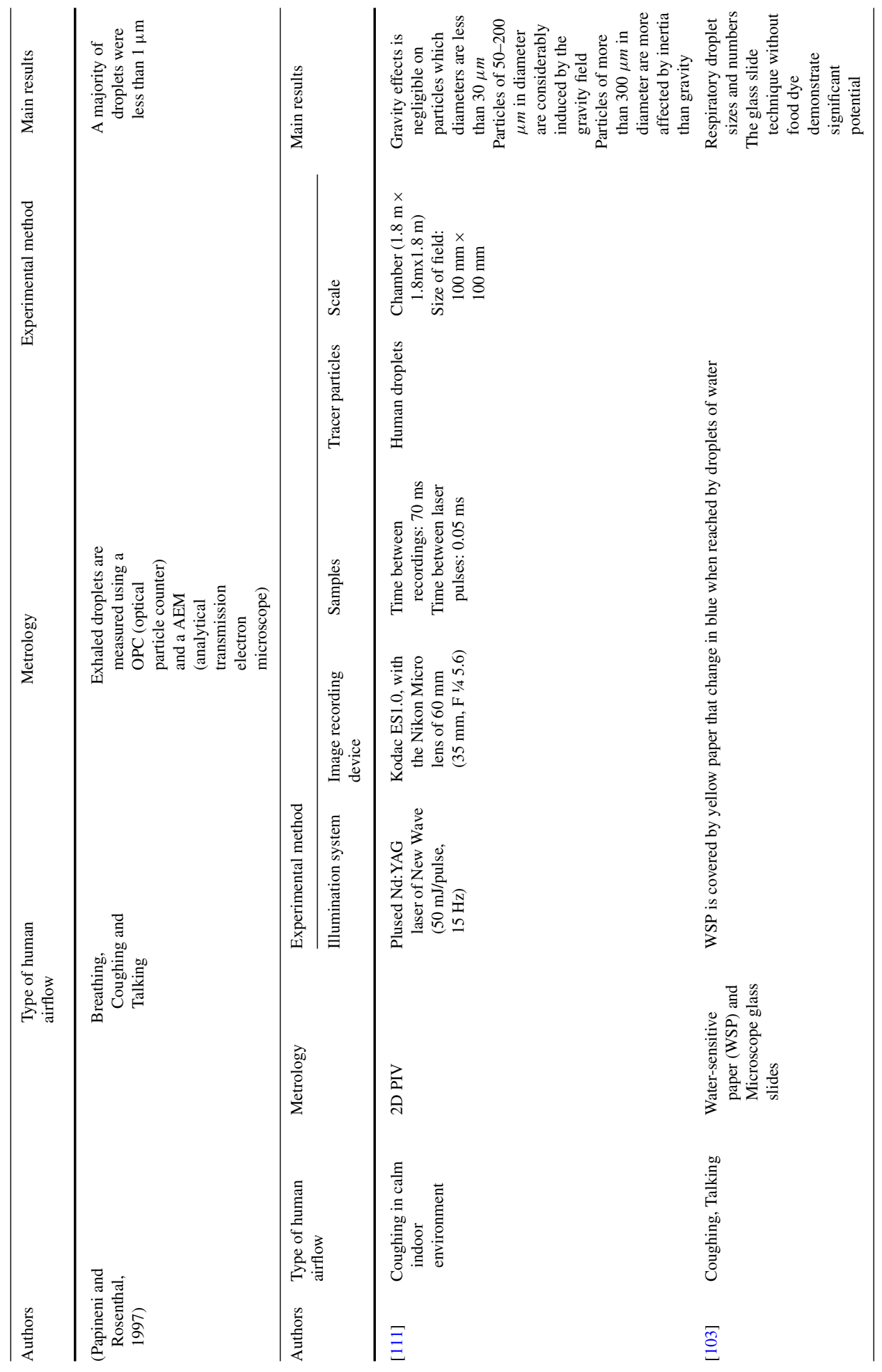




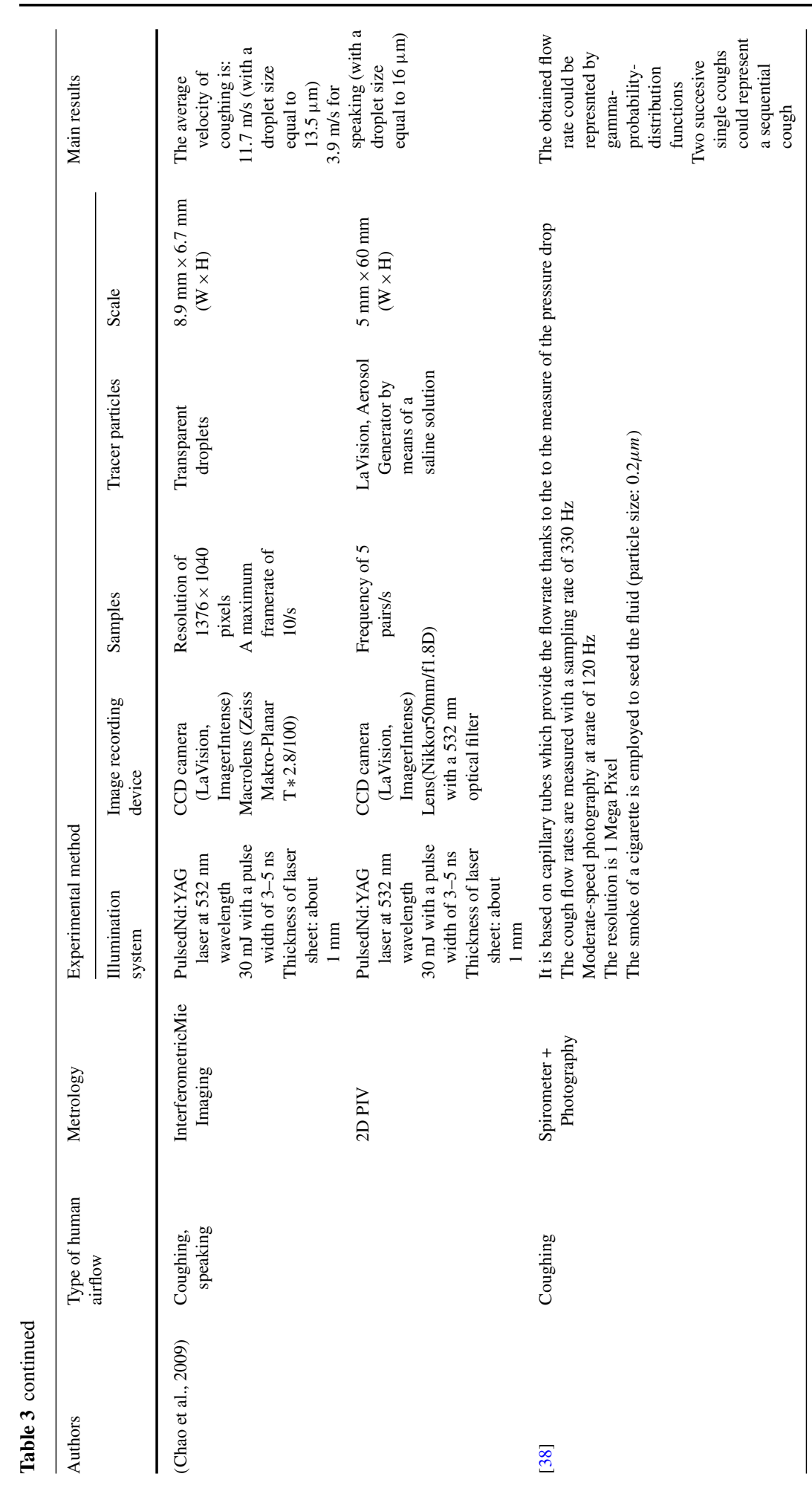




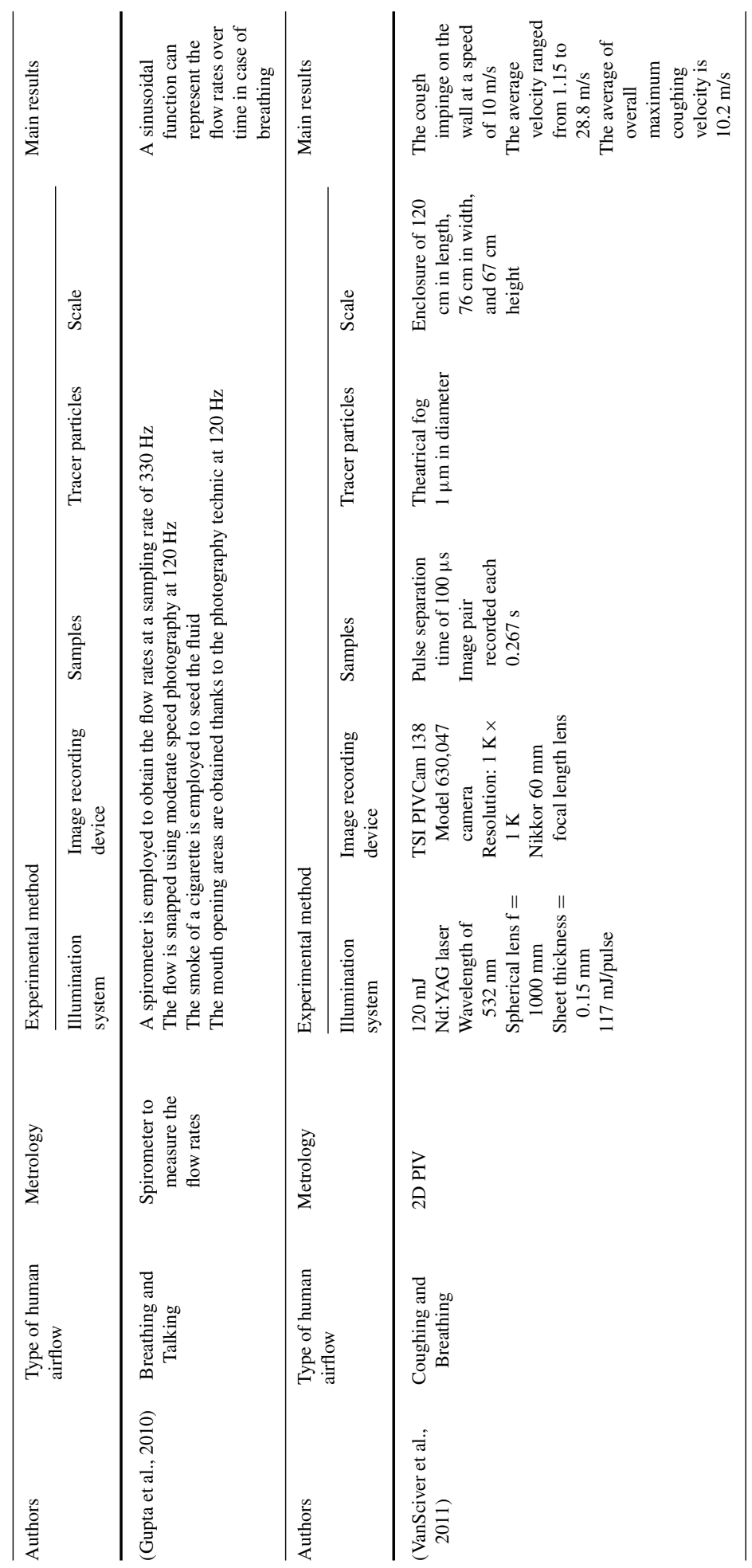

\section{照 Springer}




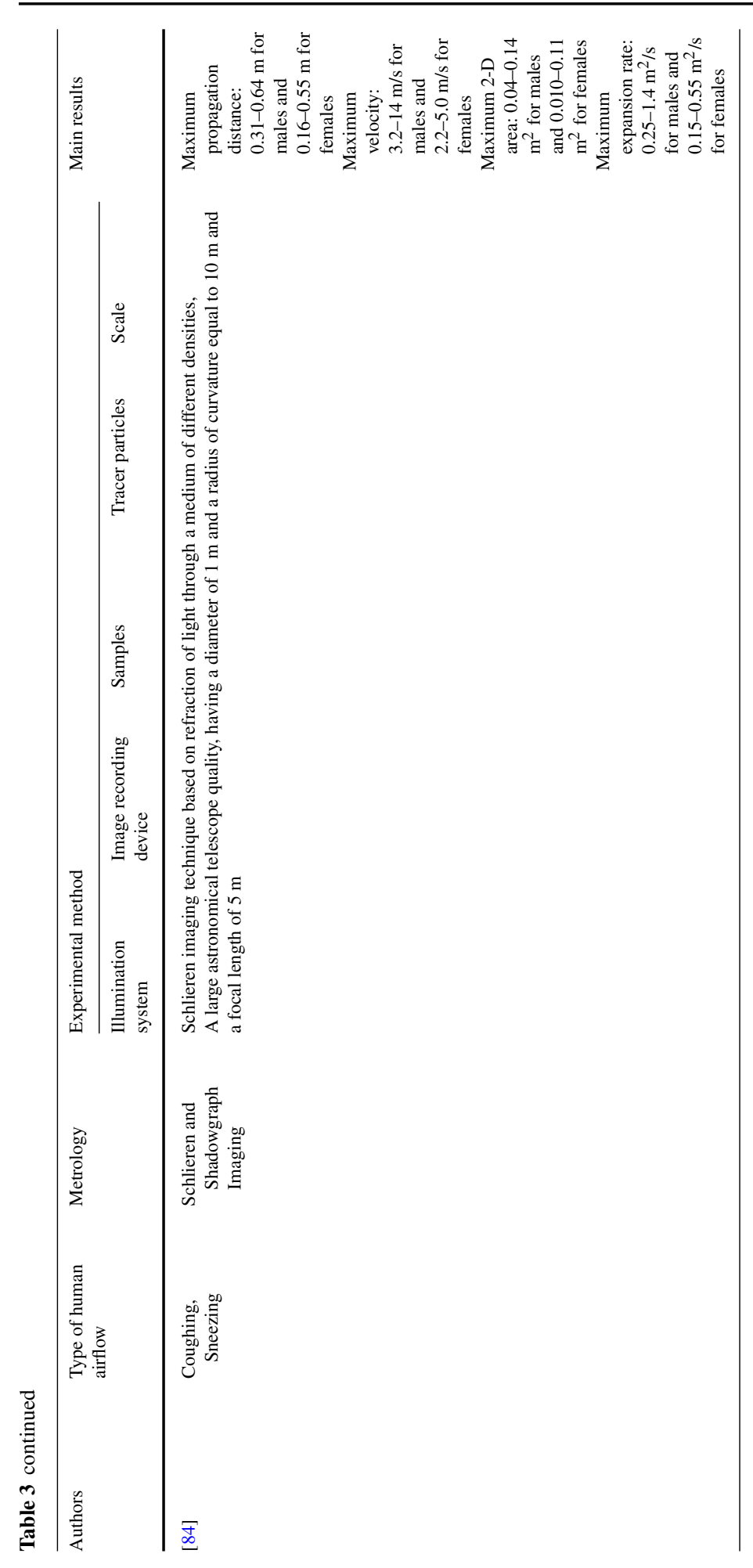




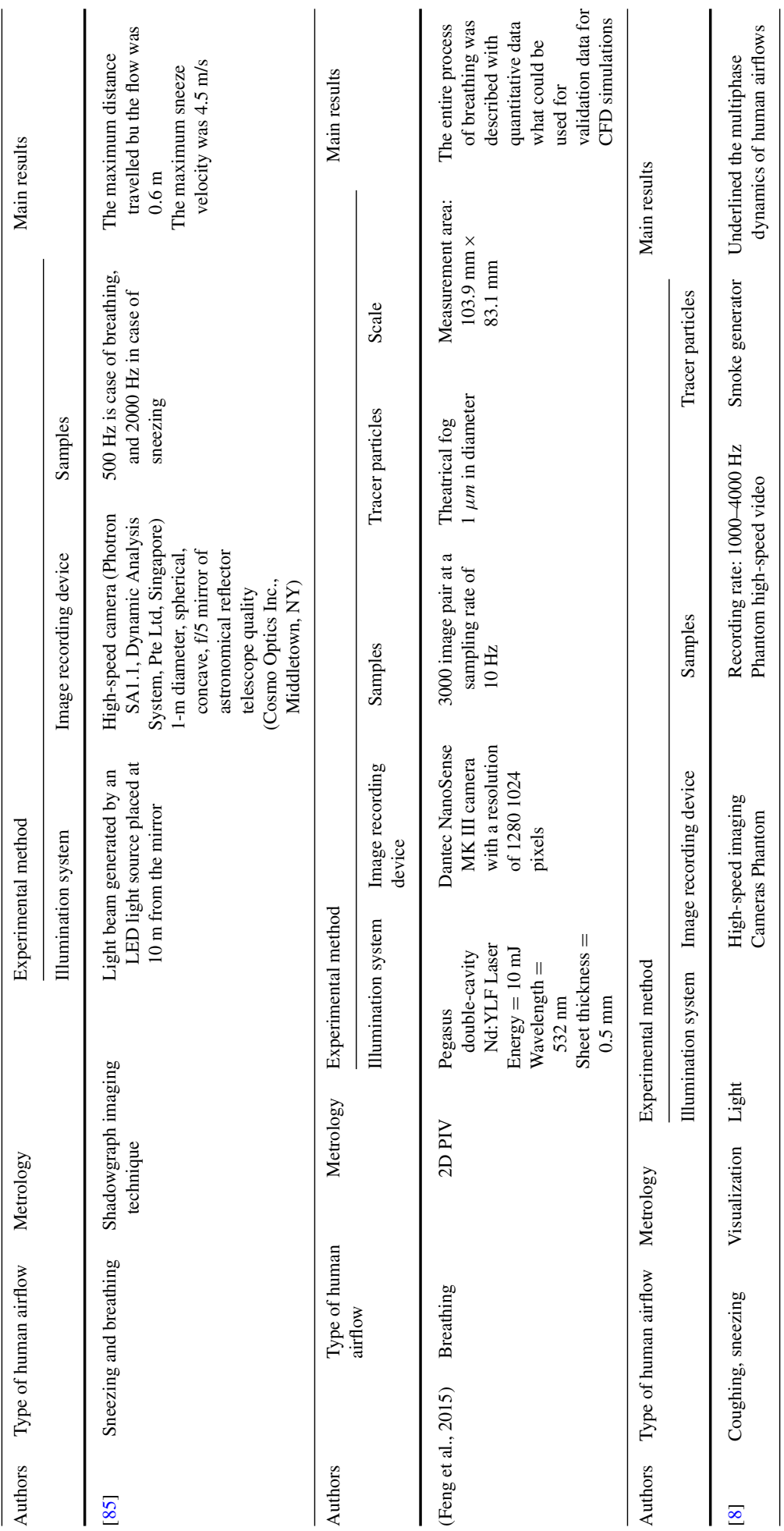




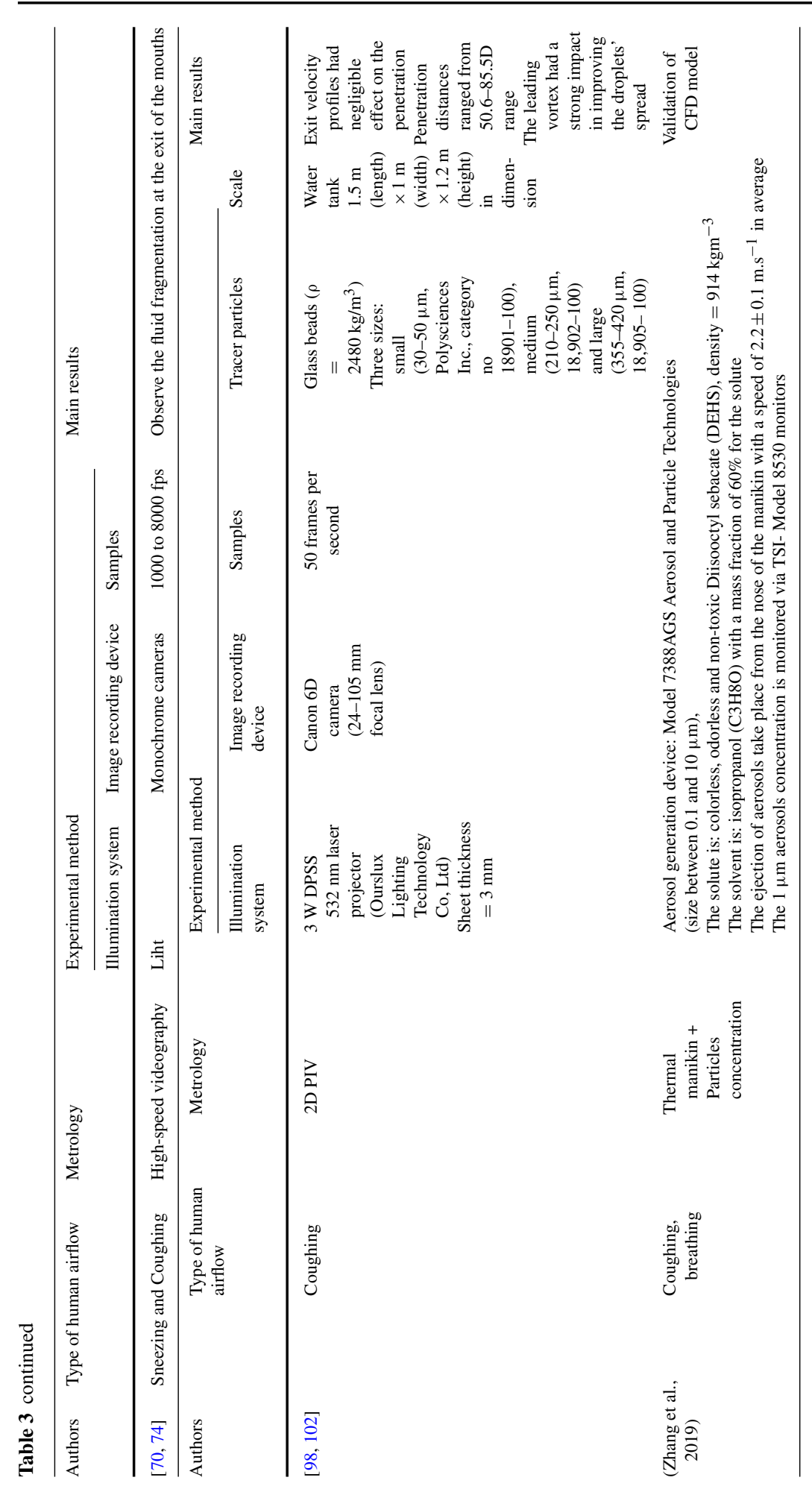



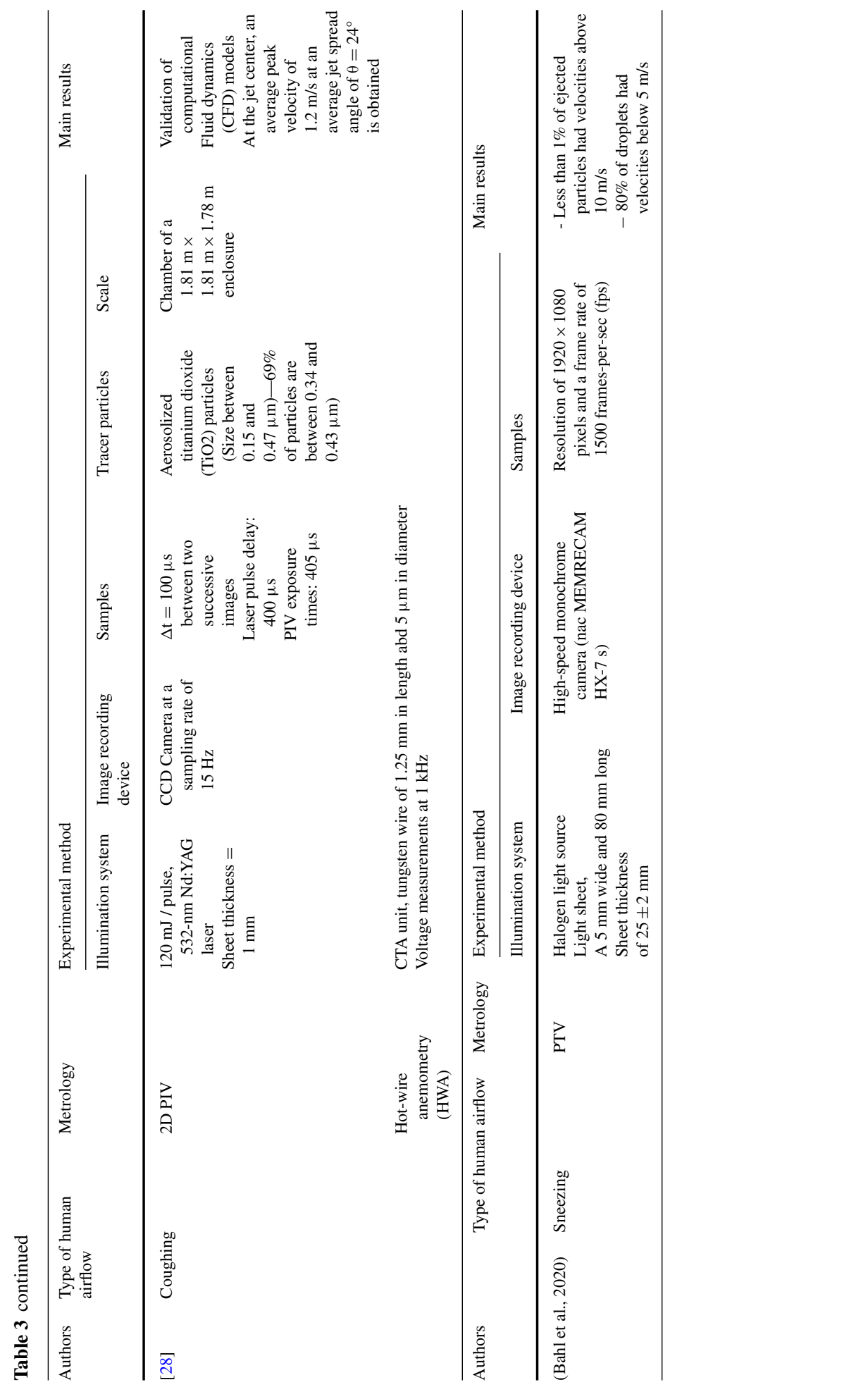


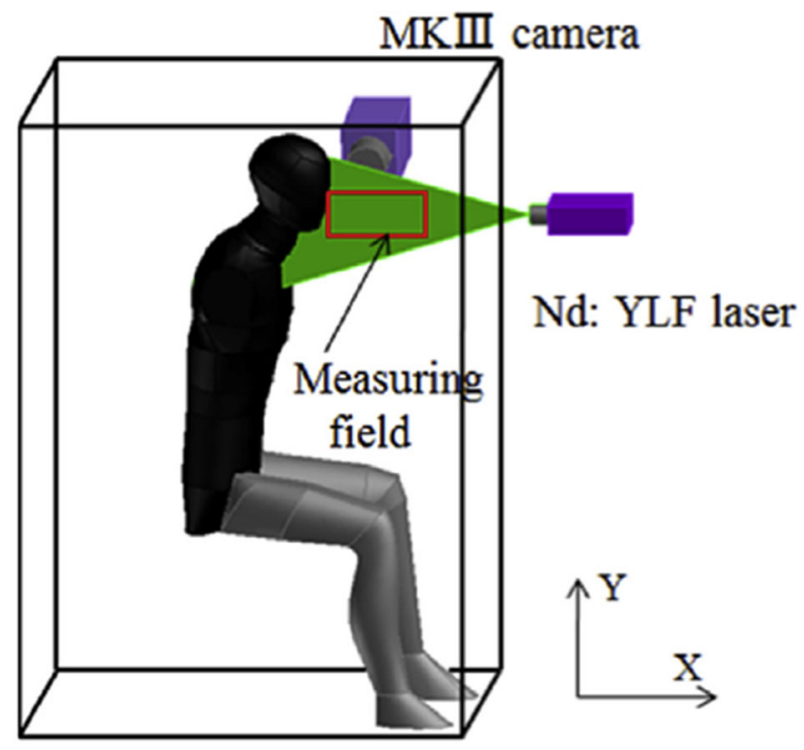

Fig. 18 Schematic of experimental platform (Feng et al. 2015)

\section{Numerical investigation of human coughing, sneezing and breathing}

Transportation of viruses can be predicted using numerical simulations, Holmes and Morawska [40]. CFD simulations were used by many authors, as they are inexpensive as compared to experimental fluid dynamics methods. Using CFD requires accurate flow boundary conditions for exhalation such as opening area (nose or mouth), temperature, flow rate and the size of the droplets Gupta et al. [38]. Using precise boundary conditions is essential for an accurate prediction of the virus transmission. Zhao et al. [109] treated these boundary conditions with an assumed temperature and a constant flow rate, direction, and area of the nose or mouth opening. In this study, transport and distribution of droplets generated by coughing and sneezing was analyzed. It was shown that sneezing and coughing produced significantly higher number of particles than normal breathing. As demonstrated in this paper, sneezing or coughing with outlet velocity of $20 \mathrm{~m} / \mathrm{s}$ would cause the droplets to travel farther than $3 \mathrm{~m}$.

Certain experimental results presented by different studies can be used to define the boundary conditions for numerical simulations. Gupta et al. [38] measured flow rates, flow directions and mouth cough openings (openings areas). Mahajan et al. [58] proposed a correlation between PVT, CPFR and CEV. Singh et al. [77] tested the relationship between PVT and CPFR for different genders, it was shown that larynx size difference in females and males could create a significant difference in the results. Zhu et al. [111] studied total cough volume. It was measured that total cough volume varied from 0.8 to 2.21 with an average of 1.41 . This study gave some important information on cough, but they did not measure the cough profile variation.

Several studies used visualization of coughing dynamics, which could be used to define the boundary conditions for CFD simulations. For example, Jennison [45] used high-speed photography to visualize the cough dynamics. Edgerton and Barstow [29] focused on the droplet size distribution. Settles et al. [72] used Schlieren imaging to study the thermal spread of a cough. Shadowgraph and schlieren techniques have been applied for clinical imaging 
[87]. A good comprehensive review of using schlieren photography for visualization human airflows was done by Clark and de Calcina-Goff [19]

$\mathrm{Si}$ et al. [76] used a k- $\omega$ turbulence model and Lagrangian particle tracking algorithm to investigate the behavior of respiratory droplets $(0.1-4 \mu \mathrm{m})$ during coughs. Boundary conditions were taken from experimental measurements. It was found that the $2-\mu \mathrm{m}$ droplets have the highest exhalation fraction of $1.6 \%$ with a mean exiting speed of $20 \mathrm{~m} / \mathrm{s}$, regardless of cough depths. The finding that most exhaled droplets from deep lungs are $2 \mu \mathrm{m}$ highlights the need for more effective facemasks in blocking 2- $\mu \mathrm{m}$ droplets and smaller both in infectious source control and self-protection from airborne virus-laden droplets.

Vuorinen et al. [94] investigated the possibility of airborne transmission of COVID-19. The authors used the Monte Carlo and LES simulations on the evolution of the cough-generated cloud within a generic public environment to provide quantitative insight on the exposure time in public indoor environments. Supermarket space was considered in this paper and based on numerical simulations it was shown that physical distancing significantly reduced the risk of infection. It was also shown that the risk of accumulating critical exposure could remain significant in the order of minutes after the cough.

Wan et al. [95] used Lagrangian-based model to simulate the transport and deposition of expiratory aerosols (including coughing) in an aircraft cabin. Their numerical predictions were validated by experiments. They used the aerosol dispersion to estimate the infection risk by inhalation and they developed a model to estimate the risk of infection by physical contact. Since significant amount of aerosols was deposited on different surfaces inside the cabin it was important to take the risk of physical transmission into consideration. It was shown that aerosols with initial sizes under $28 \mu \mathrm{m}$ in diameter could stay airborne for a long period of time and and could be transported by the air flow. The $k-\epsilon$ (RNG) turbulence model was used to simulate the motion of each expiratory droplet that was tracked by solving the momentum balance equation (in a Lagrangian frame). Three different scenarios were considered. The first two cases simulated cruising condition in the cabin with properly operating Environmental Control System (ECS) and the third case simulated major failure of ECS. A circular droplet injection outlet was created on the face of the passenger seated in the middle of the last row, who was considered as the expiratory aerosol's injection source. The injection was placed $1.1 \mathrm{~m}$ above the floor and the volume of each injection was $400 \mathrm{~mL}$ of air (one-second duration). The numerical results of Wan et al. [95] were validated with the experimental investigation of To et al. [88] using similar aircraft cabin environment and operating conditions. Particle Image Velocimetry (PIV) was used to characterize the airflows and expiratory aerosol dispersions at selected locations in the cabin and deposition of aerosol was studied using the fluorescent dye technique. It was shown that the cough jet was propagating further to the row of seats ahead and could carry a significant amount of droplets in the air flow and it was taking 20-30 s to reach the breathing zones of the passengers seated within two rows from the coughing source. It was demonstrated that $60-70 \%$ of expiratory aerosols in mass were deposited on the surfaces close to the coughing source, confirm Wan et al. [95] hypothesis about physical contact transmission.

Chong et al. [21] conducted direct numerical simulations of a turbulent jet of respiratory aerosol with a Lagrangian-Eulerian approach, which was coupled to the ambient, temperature, velocity and relative humidity $(\mathrm{RH})$. It was shown that for a $50 \% \mathrm{RH}$, the lifetime of the droplets with initial diameter of $10 \mu \mathrm{m}$ got extended by a factor of more than 30 when compared to results reported in Wells et al. [99, 100] and that larger droplets behaved ballistically. It was also shown that for $90 \% \mathrm{RH}$, the lifetime of smaller droplets was increased even more (up to 150 times). These results could explain COVID-19 outbreak on cooleddown meat-processing plant with the high ambient relative humidity Guenther et al. [37] or 


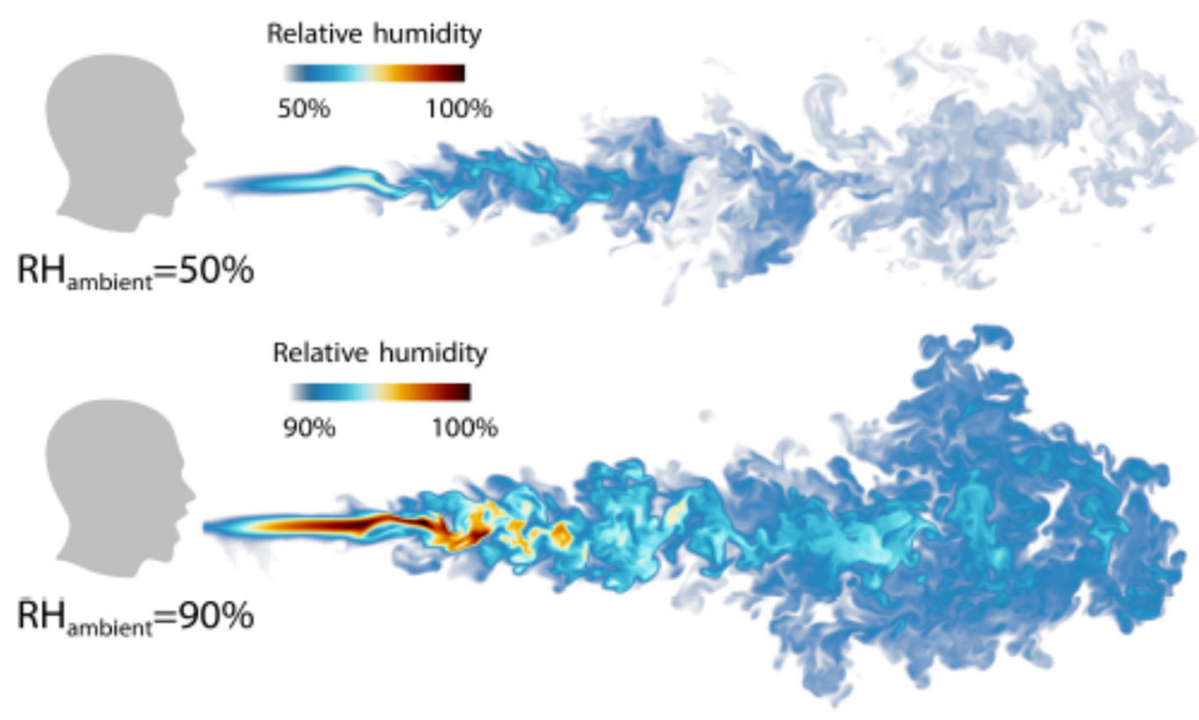

Fig. 19 Humid puff propagation at different ambient RH [21]

in the restaurants and pubs with poor ventilation. The comparison of droplets propagation for different relative humidity can be found in Fig. 19. One should notice the presence of vortical structures that resemble to that found in free jets. Therefore, investigating the entrainment mechanism and vortex dynamics would be of interest for a better understanding of the development of these jets [30, 31].

Chen et al. [14] developed numerical models for predicting airflows using smoke visualization to define the boundary conditions. It was shown that covering a cough with a tissue, a cupped hand, or an elbow could dramatically reduce horizontal velocity and made particles to move upward.. RNG k- $\varepsilon$ model was used to calculate the airflow and turbulence. In order to connect the solution variables at the near-wall cells with corresponding parameters on the walls, the logarithmic law wall function was implemented. The dispersion of exhaled particles was calculated using Eulerian drift-flux model. Initial conditions such as flow directions, initial velocities, etc. were taken from smoke visualizations. The evaporative process was considered almost instantaneous for small droplets (diameter less than $3 \mu \mathrm{m}$ ) and particles deposition effect on the walls was neglected for particle size of $1.0 \mu \mathrm{m} \mathrm{[15],}$ 110. Comparison of airflows between experiments and numerical predictions can be found in Fig. 20.

Aliabadi et al. [1] developed a CFD model for a near-field cough and sneeze droplet dispersion for studying both heat and mass transfer. Different scenarios of in cough and sneeze processes were considered as well as variations in injection volumes and ambient relative humidity. Nine different simulations for coughs and sneezes were conducted and a large number of droplets (with 1-500 $\mu \mathrm{m}$ diameters) were tracked. RNG k $-\varepsilon$ turbulence model with standard wall function and differential viscosity was used. Buoyancy effects and viscous dissipation were also considered.

Dhouk and Drikakis [23] conducted a numerical fluid dynamics study of the respiratory droplets' transmission around and through a facemask filter. Multiphase computational fluid dynamics model in a fully coupled Eulerian-Lagrangian framework was used to investigate the droplet dynamics induced by mild coughing. It was shown that masks could reduce the 


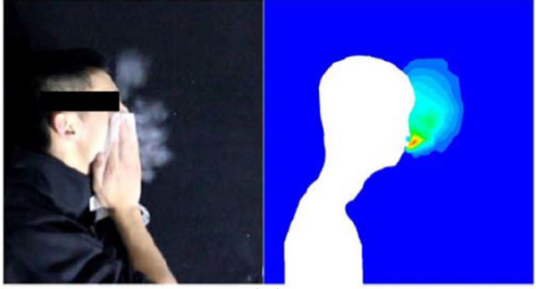

(a)

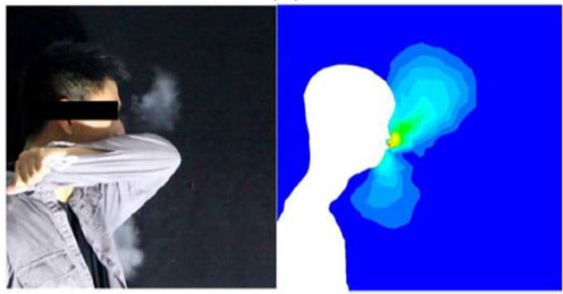

(c)

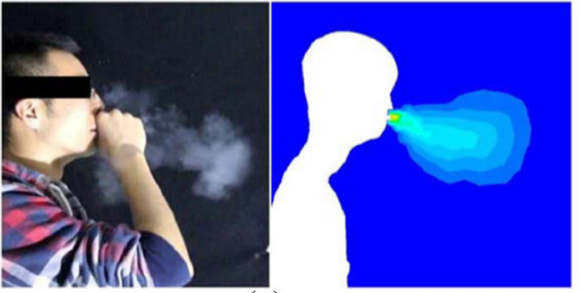

(e)

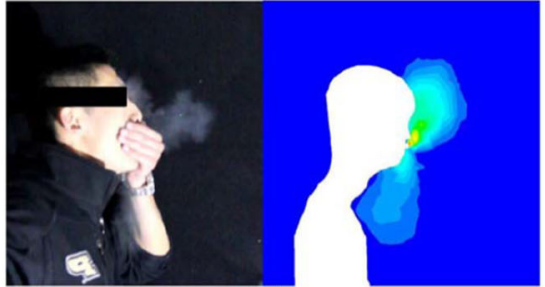

(b)

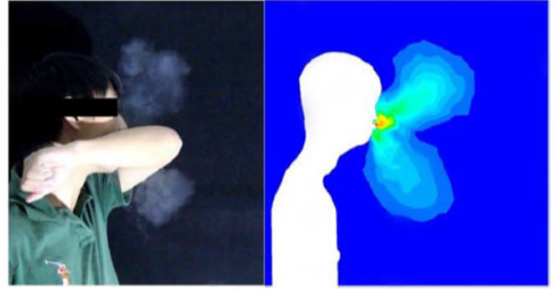

(d)

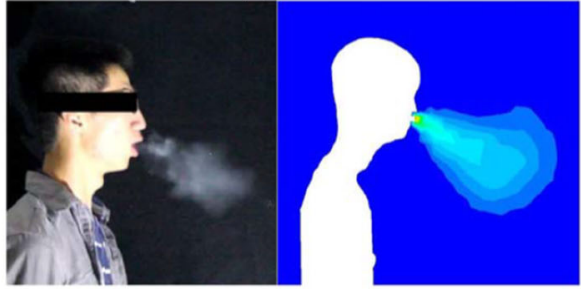

(f)

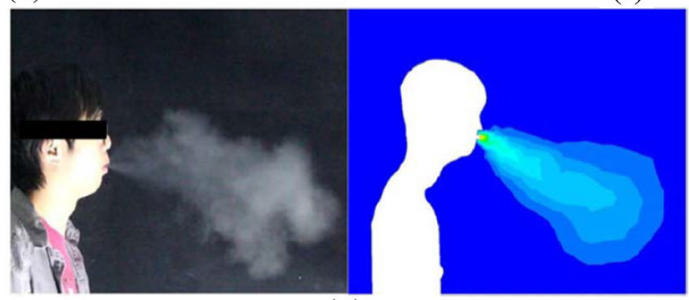

(g)

Fig. 20 Qualitative comparison of airflows: coughs covered by a a tissue, b a cupped hand, $\mathbf{c}$ an elbow with a sleeve, $\mathbf{d}$ an elbow without a sleeve, and $\mathbf{e}$ a fist; and uncovered coughs with $\mathbf{f}$ average velocity and $\mathbf{g}$ maximum velocity [14]

airborne transmission and could protect wearer from the droplets expelled from the other subjects. It was found that the criteria chosen for assessing the facemask performance must be modified to account for the dynamics of airborne droplet and the flow leakage around the filter. The main results of this study are presented in the next section.

\section{Face mask effectiveness in blocking respiratory jets and reducing the spread of germs}

In general, minute aerosols, respiratory droplets or direct contacts with human are the means of transmission of respiratory viruses [75]. The nuclei droplets (diameters $<5 \mu \mathrm{m}$ ) are termed 
Fig. 21 A subject coughing in a cyclic incident. With and without a mask (Dbouk and Drikatis 2020)
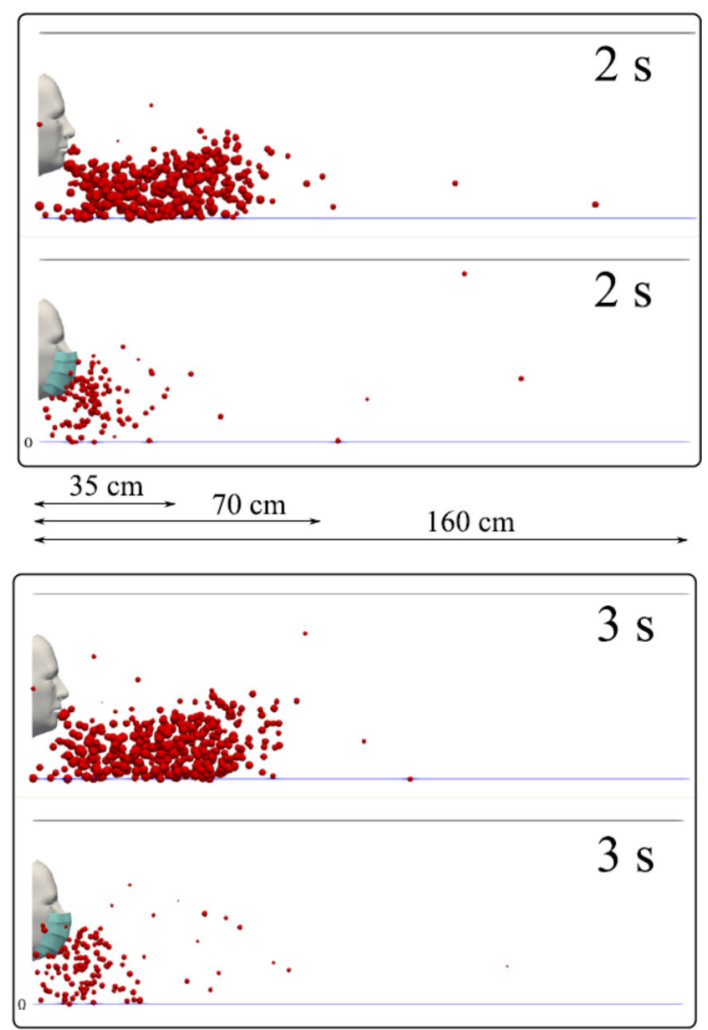

as the fine aerosols while the respiratory droplets (diameters $>5 \mu \mathrm{m}$ ) coarse aerosols. The respiratory tract can be protected from infection by the droplets and airborne aerosols wearing a facemask. Thus, the facemask decreases the chances of respiratory viral infections (RVIs) by providing a physical interference.

Numerical simulations were conducted by Dbouk and Drikatis [23] with and without a mask. It was shown that wearing a facemask significantly reduces the droplet cloud; however, some droplets can still travel to a distance farther than one meter. It was also shown that facemask reduces the lateral dispersion of droplet, but it does not eliminate it. The comparison of some cyclic coughing results with and without the facemask is shown in Fig. 21. The surrounding conditions were as follows: zero wind speed, ambient temperature of $20{ }^{\circ} \mathrm{C}$, pressure of $1 \mathrm{~atm}$, and relative humidity equal to $50 \%$. It can be seen that for the two phases presented, many droplets penetrate the mask shield and some saliva droplet disease-carrier particles can travel more than $1.2 \mathrm{~m}$.

Many studies have proved that a coughing or sneezing person transmit the coronavirus containing droplets for several meters. The variation of the sizes of these particles affect the dispersion distance from the source during their journey through the air. Comparatively bigger particles will gather on the surfaces of laptops, desks, chairs, or other items of the surroundings [62]. On the other hand, the smaller particles will suspend in the air for a longer period of time and later will travel to distant places depending on the airflow. Because of the small size and low velocity of aerosols, they are capable of staying in air for a longer period, 
e.g. $10 \mathrm{~s}$ for $100 \mu \mathrm{m}, 4 \mathrm{~min}$ for $20 \mu \mathrm{m}, 17 \mathrm{~min}$ for $10 \mu \mathrm{m}$ and $62 \mathrm{~min}$ for $5 \mu \mathrm{m}$ in a $3-\mathrm{m}$ fall [48].

However, public health authorities advised the implementation of several preventive measures such as the use of face masks in public settings and maintaining social-distancing. Face masks have been reported as an effective measure in lowering the transmission of the virus [18, 56]. The broad usage of facemasks is unavoidable in metropolitan cities due to close contact among people in public transportations, workplace and shopping malls. Despite numerous research efforts, the effectiveness of using facemask for preventing virus-transmitting droplets are still controversial and results are not seen as conclusive (Jacob et al., 2009; Cowling et al., 2008). In Asian countries, facemasks are routinely used by the individuals in public settings to reduce the risk to airborne pathogens.

Although, some recent studies show that facemasks appreciably reduce the risk of contracting influenza and other viruses [2, 63, 79]. Noti et al. [63] discovered that tightly sealed masks are capable of blocking the entrance of viruses by $95 \%$. However, the tightly sealed respirators can restrict the entry of both types of viruses in the respiratory tract by $>99.6 \%$. Though only $<70 \%$ blockage of the infectious and total viruses occurs in the cases that the respirators are poorly fitted and masks are loosely fitted.

Wang et al. [97] reviewed the efficacy of surgical masks and found that surgical masks are not associated with acute respiratory incidence, indicating that surgical masks may not be effective in preventing acute respiratory illnesses. Stutt et al. [79] reported that when 100\% individuals use facemask, there is significantly less disease spread and they assumed facemasks are 50\% effective to capture exhaled virus inoculum. Alfelali et al. (2020) conducted a large-scale cluster randomized controlled trial to assess the effectiveness of facemasks among Hajj pilgrims against virus respiratory infections and they found that facemasks use is not effective against virus due to poor compliance with facemask use.

However, different studies show that cloth masks can filter fine droplets and particles less than 10 microns and it can reduce wearer exposure from droplets contacting viruses and bacteria through filtration. Multilayer cloth face masks with higher thread counts have shown better reduction in virus transmission than single layer cloth face masks $[90,49,66$, 57]. Table 4 represents recent studies of randomized controlled trials and technical meta review for assessing facemasks in prevention of respiratory virus transmission in healthcare and public settings.

\section{Conclusion}

The understanding of the COVID-19 transmission is of high importance to limit its spread which is strongly dependent on the flow dynamics of the human airflows. In the present paper, the transmission of contagious diseases, such as COVID-19, is discussed based on literature review of the experimental and numerical investigations on human airflows and their impact on infectious disease transmission was presented. The effectiveness of wearing facemask to reduce the transmission of infectious diseases was also discussed. The main conclusions can be summarized as follows:

1. Different human airflows including coughing, sneezing and breathing can participate through specific mechanisms to the transmission of COVID-19. Several studies have proved that a coughing or sneezing person can transmit the COVID-19 containing droplets from several meters distance. However, the variation of sizes of these particles affects the propagation distance of these droplets through the air. 


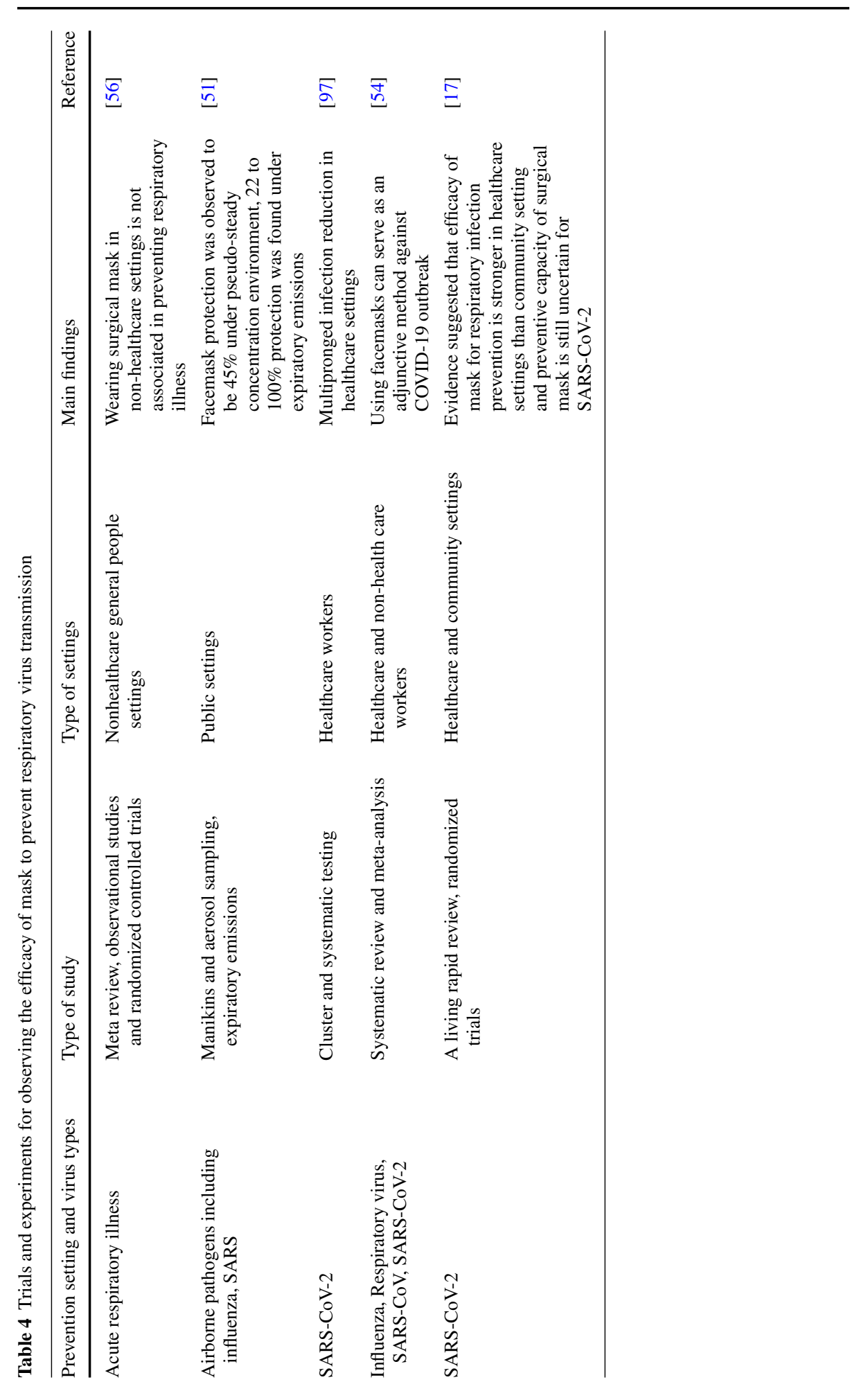




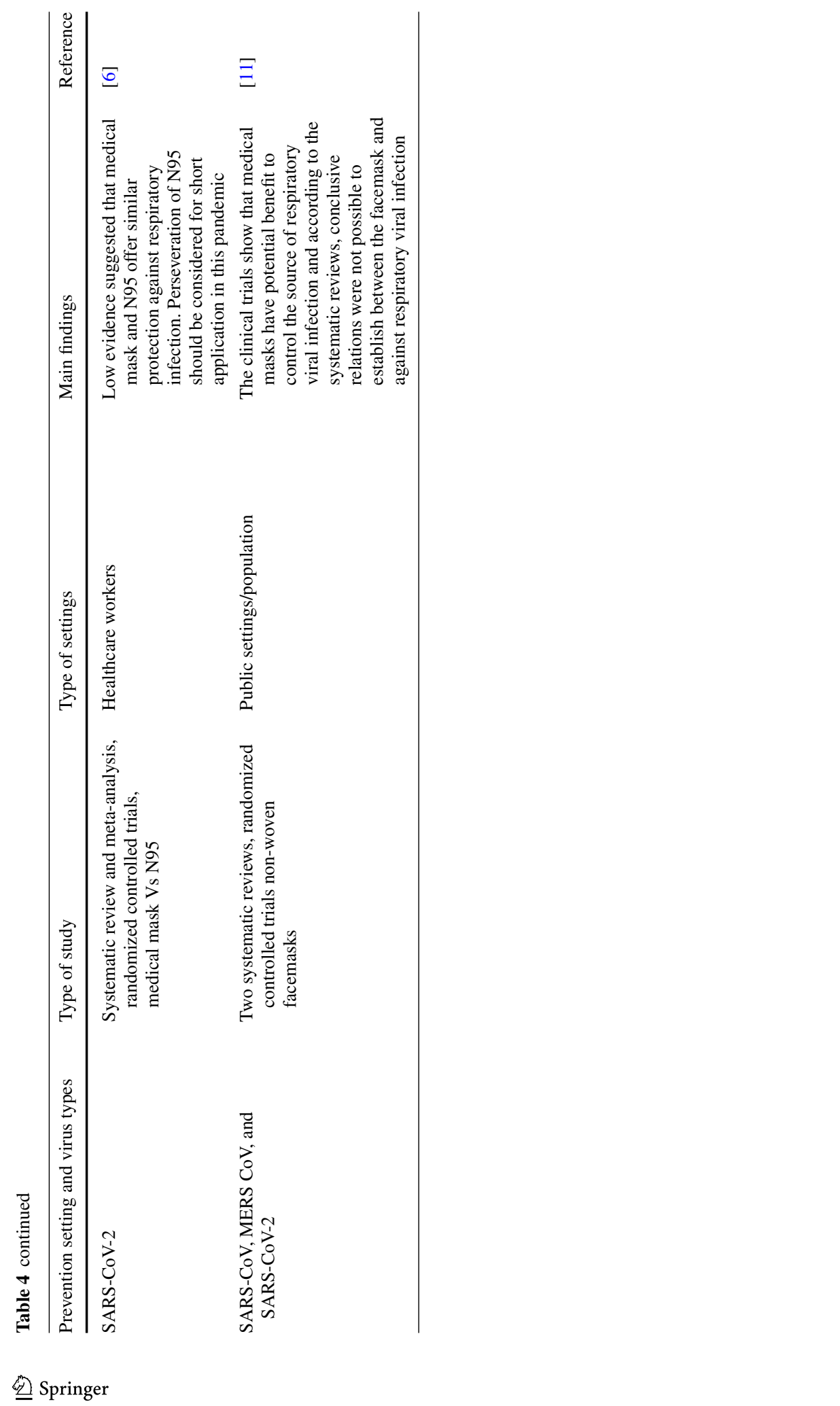


2. The smaller cough droplets can reach longer distance than those of sneezing. In addition, the sneeze cloud was found to be denser than that of coughing. It was demonstrated that the viscoelasticity plays a major role in the final droplet size distribution. Higher fluid viscosity and surface tension are mostly in favor of large droplets. It was also evidenced that the lifetime of the droplets dramatically increases for higher relative humidity (RH), with a lifetime of smaller droplets increased by 30 times for a $\mathrm{RH}$ of $50 \%$ and up to 150 times for RH of $90 \%$. A good ventilation with controlled $\mathrm{RH}$ is thus of high importance to limit the COVID-19 transmission in closed environments.

3. The stream distance penetration was found to be mainly dependent on the mouth opening (jet diameter) rather than the temporal exit velocity profiles. Due to the existence of a leading vortex, small and medium particles had a similar penetration; whereas large particles drop at short distance. No significant difference was found between healthy and sick volunteers. It was also found that the propagation distance and the maximum velocity of droplets depends on both the droplet size and the patient gender. Higher peak velocities and longer propagation distance were observed for males.

4. Using CFD to simulate human airflows involved in virus transmission requires accurate flow boundary conditions for exhalation such as; nose or mouth opening area, flow rate, temperature, and size distribution of the droplets. It was shown that using DNS provides a much more accurate numerical prediction of the droplet dynamics when compared to RANS models. High-resolution LES simulations on cough generated aerosol cloud evolution also provided a good quantitative insight to the exposure time in different public indoor environments.

5. It was reported that facemasks are an effective measure in lowering the transmission of Covid-19. It was also shown that cloth masks can filter fine droplets and particles less than 10 microns with an enhanced protection reported using multilayer cloth facemasks.

\section{References}

1. A.A. Aliabadi, S. Rogak, S. Green, K.H. Bartlett, CFD simulation of human coughs and sneezes: a study in droplet dispersion, heat, and mass transfer, in Proceedings of the ASME 2010 International Mechanical Engineering Congress \& Exposition (IMECE2010), pp. 1051-1060 (2010)

2. M. Alfelali, E.A. Haworth, O. Barasheed, A.-M. Badahdah, H. Bokhary, M. Tashani, M.I. Azeem, J. Kok, J. Taylor, E.H. Barnes, H. El Bashir, G. Khandaker et al., Facemask against viral respiratory infections among Hajj pilgrims: A challenging cluster-randomized trial. PLoS ONE 15, e0240287 (2020)

3. G.S. Bhat, R. Narasimha, A volumetrically heated jet: large-eddy structure and entrainment characteristics. J. Fluid Mech. 325, 303-330 (1996)

4. R. Bansil, B.S. Turner, Mucin structure, aggregation, physiological functions and biomedical applications. Curr. Opin. Colloid Interface Sci. 11(2-3), 164-170 (2006)

5. P. Bahl, C.M. de Silva, A.A. Chughtai, C.R. MacIntyre, C. Doolan, An experimental framework to capture the flow dynamics of droplets expelled by a sneeze. Exp. Fluids 61(8), 176 (2020). https://doi. org/10.1007/s00348-020-03008-3

6. J.J. Bartoszko, M.A.M. Farooqi, W. Alhazzani, M. Loeb, Medical masks vs N95 respirators for preventing COVID-19 in healthcare workers: a systematic review and meta-analysis of randomized trials. Influenza Other Respir. Viruses 14, 365-373 (2020)

7. T. Bongers, B.R. O'Driscoll, Effects of equipment and technique on peak flow measurements. BMC Pulm. Med. 6(1), 14 (2006). https://doi.org/10.1186/1471-2466-6-14

8. L. Bourouiba, E. Dehandschoewercker, J.W. Bush, Violent expiratory events: on coughing and sneezing. J. Fluid Mech. 745, 537-563 (2014)

9. L. Bourouiba, Understanding the transmission of H5N1. CAB Rev 17, 1-9 (2013)

10. L. Bourouiba, Turbulent gas clouds and respiratory pathogen emissions: potential implications for reducing transmission of COVID-19. JAMA 323, 1837-38 (2020) 
11. M.C.D. Camargo, M.S. Martinez-Silveira, A.A. Lima, B.P. Bastos, S. Dld, S.E.D.C. Mota, R.B. Silva, I.P.D. Toledo, Effectiveness of the use of non-woven face mask to prevent coronavirus infections in the general population: a rapid systematic review. Ciência Saúde Coletiva 25, 3365 (2020)

12. Centers for Disease Control and Prevention. COVID-19 Pandemic Planning Scenarios. 2021, March 19 (cited 202126 May); Available from: https://www.cdc.gov/coronavirus/2019-ncov/hcp/planningscenarios.html

13. C.Y.H. Chao et al., Characterization of expiration air jets and droplet size distributions immediately at the mouth opening. J. Aerosol Sci. 40(2), 122-133 (2009). https://doi.org/10.1016/j.jaerosci.2008.10. 003

14. C. Chen, C.-H. Lin, Z. Jiang, Q. Chen, Simplified models for exhaled airflow from a cough with the mouth covered. Indoor Air 24(6), 580-591 (2014)

15. C. Chen, B. Zhao, Some questions on dispersion of human exhaled droplets in ventilation room: answers from numerical investigation. Indoor Air 20, 95-111 (2010)

16. T.M. Chen, J. Rui, Q.P. Wang, Z.Y. Zhao, J.A. Cui, L. Yin, A mathematical model for simulating the phase-based transmissibility of a novel coronavirus. Infect. Dis. Poverty 9(1), 1-8 (2020)

17. R. Chou, T. Dana, R. Jungbauer, C. Weeks, M.S. McDonagh, Masks for prevention of respiratory virus infections, including SARS-CoV-2, in health care and community settings : a living rapid review. Ann. Intern Med. 173, 542-555 (2020)

18. M.A. Chowdhury, M.B.A. Shuvho, M.A. Shahid, A.K.M.M. Haque, M.A. Kashem, S.S. Lam, H.C. Ong, M.A. Uddin, M. Mofijur, Prospect of biobased antiviral face mask to limit the coronavirus outbreak. Environ. Res. 192, 110294 (2021)

19. R.P. Clark, M.L. de Calcina-Goff, Some aspects of the airborne transmission of infection. J. R. Soc. Interface 6(Suppl_6), S767-S782 (2009)

20. B.J. Cowling, R.O. Fung, C.K. Cheng, V.J. Fang, K.H. Chan, W.H. Seto, R. Yung, B. Chiu, P. Lee, T.M. Uyeki, P.M. Houck, J.S. Peiris, G.M. Leung, Preliminary findings of a randomized trial of nonpharmaceutical interventions to prevent influenza transmission in households. PLoS ONE 3, e2101 (2008)

21. K.L. Chong, C.S. Ng, N. Hori, R. Yang, R. Verzicco, D. Lohse, Extended lifetime of respiratory droplets in a turbulent vapour puff and its implications on airborne disease transmission. Phys. Rev. Lett. (2020). https://doi.org/10.1101/2020.08.04.20168468

22. D. Talib, D. Dimitris, On respiratory droplets and face masks. Phys. Fluids 32, 063303 (2020). https:// doi.org/10.1063/5.0015044

23. T. Dbouk, D. Drikakis, On coughing and airborne droplet transmission to humans. Phys. Fluids 32, 053310 (2020)

24. J. Dekker, J.W. Rossen, H.A. Büller, A.W. Einerhand, The MUC family: an obituary. Trends Biochem. Sci. 27(3), 126-131 (2002)

25. S.S. Diwan, S. Ravichandran, R. Govindarajan, R. Narasimha, Understanding transmission dynamics of COVID-19-type infections by direct numerical simulations of cough/sneeze flows. Trans. Indian Natl. Acad. Eng. 5, 255-261 (2020)

26. S.S. Diwan, P. Prasanth, K.R. Sreenivas, S.M. Deshpande, R. Narasimha, Cumulus-type flows in the laboratory and on the computer: Simulating cloud form, evolution, and large-scale structure. Bull. Am. Meteor. Soc. 95(10), 1541-1548 (2014)

27. J.P. Duguid, The size and the duration of air-carriage of respiratory droplets and droplet-nuclei. J. Hyg. 44(6), 471-479 (1946)

28. N. Dudalski, A. Mohamed, S. Mubareka, R. Bi, C. Zhang, E. Savory, Experimental investigation of far-field human cough airflows from healthy and influenza-infected subjects. Indoor Air 30, 966-977 (2020). https://doi.org/10.1111/ina.12680

29. H.E. Edgerton, F.E. Barstow, Multiflash photography. Photogr. Sci. Eng. 3(6), 288-291 (1959)

30. M. El Hassan, A. Meslem, Time-resolved stereoscopic particle image velocimetry investigation of the entrainment in the near field of circular and daisy-shaped orifice jets. Phys. Fluids 22, 035107 (2010). https://doi.org/10.1063/1.3358465

31. M. El Hassan, A. Meslem, K. Abed-Meraim, Experimental investigation of the flow in the near-field of a cross-shaped orifice jet. Phys. Fluids 23, 045101 (2011)

32. E.J. Emanuel, G. Persad, R. Upshur, B. Thome, M. Parker, A. Glickman, C. Zhang, C. Boyle, M. Smith, J.P. Phillips, Fair allocation of scarce medical resources in the time of covid-19. N. Engl. J. Med. 382, 2049-2055 (2020)

33. L. Feng, S. Yao, H. Sun, N. Jiang, J. Liu, TR-PIV measurement of exhaled flow using a breathing thermal manikin. Build. Environ. 94, 683-693 (2015). https://doi.org/10.1016/j.buildenv.2015.11.001

34. W.J. Glantschnig, S.-H. Chen, Light scattering from water droplets in the geometrical optics approximation. Appl. Opt. 20(14), 2499-2509 (1981). https://doi.org/10.1364/AO.20.002499 
35. A.R. Glover, S.M. Skippon, R.D. Boyle, Interferometric laser imaging for droplet sizing: a method for droplet-size measurement in sparse spray systems. Appl. Opt. 34(36), 8409-8421 (1995). https://doi. org/10.1364/AO.34.008409

36. R. Govindarajan, Universal behavior of entrainment due to coherent structures in turbulent shear flow. Phys. Rev. Lett. 88(13), 134503 (2002)

37. T. Guenther et al. Investigation of a superspreading event preceding the largest meat processing plantrelated SARS-Coronavirus 2 outbreak in Germany (2020)

38. J.K. Gupta, C.H. Lin, Q. Chen, Flow dynamics and characterization of a cough. Indoor Air 19(6), 517-525 (2009)

39. J.K. Gupta, C.-H. Lin, Q. Chen, Characterizing exhaled airflow from breathing and talking. Indoor Air 20(1), 31-39 (2010). https://doi.org/10.1111/j.1600-0668.2009.00623.x

40. N.S. Holmes, L. Morawska, A review of dispersion modelling and its application to the dispersion of particles: an overview of different dispersion models available. Atmos. Environ. 40(30), 5902-5928 (2006)

41. S. Inouye, Y. Matsudaira, Y. Sugihara, Masks for influenza patients: measurement of airflow from the mouth. Jpn. J. Infect. Dis. 59(3), 179-181 (2006)

42. J.L. Jacobs, S. Ohde, O. Takahashi, Y. Tokuda, F. Omata, T. Fukui, Use of surgical face masks to reduce the incidence of the common cold among health care workers in Japan: a randomized controlled trial. Am. J. Infect. Control 37, 417-419 (2009)

43. K. Javorka, Z. Tomori, L. Zavarská, Mechanics of breathing during sneezing and crying in premature newborns. Eur J Respir Dis 63(5), 442-448 (1982)

44. M.W. Jennison, H.E. Edgerton, Droplet Infection of Air: Hih-speed Photoraphy of Droplet Production by Sneezin.*. Proc. Soc. Exp. Biol. Med. 43(3), 455-458 (1940). https://doi.org/10.3181/00379727-43$11230 \mathrm{P}$

45. M. W. Jennison, Atomizing of mouth and nose secretions into the air as revealed by high-speed photography (1941)

46. C.J. Kähler, R. Hain, Fundamental protective mechanisms of face masks against droplet infections. J. Aerosol Sci. 148, 105617 (2020)

47. D. Kang, H. Choi, J. H. Kim, J. Choi, Spatial epidemic dynamics of the COVID-19 outbreak in China. Int. J. Infect. Dis. (2020)

48. V. Knight, Viruses as agents of airborne contagion. Ann. N. Y. Acad. Sci. 353, 147-156 (1980)

49. A. Konda, A. Prakash, G.A. Moss, M. Schmoldt, G.D. Grant, S. Guha, Aerosol filtration efficiency of common fabrics used in respiratory cloth masks. ACS Nano 14, 6339-6347 (2020)

50. S.-B. Kwon et al., Study on the initial velocity distribution of exhaled air from coughing and speaking. Chemosphere 87(11), 1260-1264 (2012). https://doi.org/10.1016/j.chemosphere.2012.01.032

51. A.C.K. Lai, C.K.M. Poon, A.C.T. Cheung, Effectiveness of facemasks to reduce exposure hazards for airborne infections among general populations. J. R. Soc. Interface 9, 938-948 (2012)

52. S.A. Lauer, K.H. Grantz, Q. Bi, F.K. Jones, Q. Zheng, H.R. Meredith, A.S. Azman, N.G. Reich, J. Lessler, The incubation period of coronavirus disease 2019 (COVID-19) from publicly reported confirmed cases: estimation and application. Ann. Intern. Med. 172, 577-582 (2020)

53. M.T. Li, Z. Jin, G.Q. Sun, J. Zhang, Modeling direct and indirect disease transmission using multi-group model. J. Math. Anal. Appl. 446(2), 1292-1309 (2017)

54. M. Liang, L. Gao, C. Cheng, Q. Zhou, J.P. Uy, K. Heiner, C. Sun, Efficacy of face mask in preventing respiratory virus transmission: A systematic review and meta-analysis. Travel Med Infect Dis 36, 101751 (2020)

55. Q. Lin, S. Zhao, D. Gao, Y. Lou, S. Yang, S.S. Musa, D. He, A conceptual model for the outbreak of Coronavirus disease 2019 (COVID-19) in Wuhan, China with individual reaction and governmental action. Int J Infect Dis 93, 211-216 (2020)

56. X. Liu, S. Zhang, COVID-19: Face masks and human-to-human transmission. Influenza Other Respir. Viruses 14, 472-473 (2020)

57. K.D. Long, E.V. Woodburn, I.C. Berg, V. Chen, W.S. Scott, Measurement of filtration efficiencies of healthcare and consumer materials using modified respirator fit tester setup. PLoS ONE 15, e0240499 (2020)

58. R.P. Mahajan, P. Singh, G.E. Murty, A.R. Aitkenhead, Relationship between expired lung volume, peak flow rate and peak velocity time during a voluntary cough manoeuvre. Br. J. Anaesth. 72(3), 298-301 (1994). https://doi.org/10.1093/bja/72.3.298

59. D.K. Milton, M.P. Fabian, B.J. Cowling, M.L. Grantham, J.J. McDevitt, 'Influenza virus aerosols in human exhaled breath: particle size culturability, and effect of surgical masks.' PLoS Pathog. 9(3), e1003205 (2013). https://doi.org/10.1371/journal.ppat.1003205 
60. L.J.G.R. Morawska, G.R. Johnson, Z.D. Ristovski, M. Hargreaves, K. Mengersen, S. Corbett, D. Katoshevski, Size distribution and sites of origin of droplets expelled from the human respiratory tract during expiratory activities. J. Aerosol Sci. 40(3), 256-269 (2009)

61. R. Narasimha, S.S. Diwan, S. Duvvuri, K.R. Sreenivas, G.S. Bhat, Laboratory simulations show diabatic heating drives cumulus-cloud evolution and entrainment. Proc. Natl. Acad. Sci. 108(39), 16164-16169 (2011)

62. M. Nicas, W.W. Nazaroff, A. Hubbard, Toward understanding the risk of secondary airborne infection: emission of respirable pathogens. J. Occup. Environ. Hyg. 2, 143-154 (2005)

63. J.D. Noti, W.G. Lindsley, F.M. Blachere, G. Cao, M.L. Kashon, R.E. Thewlis, C.M. McMillen, W.P. King, J.V. Szalajda, D.H. Beezhold, Detection of infectious influenza virus in cough aerosols generated in a simulated patient examination room. Clin. Infect. Dis. 54, 1569-1577 (2012)

64. R.S. Papineni, F.S. Rosenthal, The size distribution of droplets in the exhaled breath of healthy human subjects. J. Aerosol Med. 10(2), 105-116 (1997). https://doi.org/10.1089/jam.1997.10.105

65. S. Ravichandran, R. Govindarajan, Vortex-dipole collapse induced by droplet inertia and phase change. J Fluid Mech. 832, 745-776 (2017). https://doi.org/10.1017/jfm.2017.677

66. S. Rengasamy, B. Eimer, R.E. Shaffer, Simple respiratory protection-evaluation of the filtration performance of cloth masks and common fabric materials against $20-1000 \mathrm{~nm}$ size particles. Ann. Occup. Hyg. 54, 789-798 (2010)

67. S. Ruan, Likelihood of survival of coronavirus disease 2019. Lancet. Infect. Dis 20(6), 630-631 (2020)

68. J. Sancho, E. Servera, J. Díaz, J. Marín, Comparison of peak cough flows measured by pneumotachograph and a portable peak flow meter. Am J Phys Med Rehabil 83(8), 608-612 (2004). https://doi.org/10.1097/ 01.phm.0000133431.70907.a2

69. Ö. Savas, A visual study in the near field of turbulent jets and implications for estimating accidental discharges. Exp Fluids 53(5), 1501-1514 (2012)

70. B.E. Scharfman, B.E. Scharfman, A.H. Techet, A.H. Techet, J.W.M. Bush, J.W.M. Bush, L. Bourouiba, Visualization of sneeze ejecta: Steps of fluid fragmentation leading to respiratory droplets. Exp. Fluids 57(2), 1-9 (2016). https://doi.org/10.1007/s00348-015-2078-4

71. R.G. Schipper, E. Silletti, M.H. Vingerhoeds, Saliva as research material: biochemical, physicochemical and practical aspects. Arch. Oral Biol. 52(12), 1114-1135 (2007)

72. G.S. Settles, E.B. Hackett, J.D. Miller, L.M. Weinstein, Full-scale schlieren flow visualization. Flow Vis. 7, 2-13 (1995)

73. G.S. Settles, Fluid mechanics and homeland security. Annu. Rev. Fluid Mech. 38, 87-110 (2006)

74. B.E. Scharfman, A.H. Techet, J.W.M. Bush, L. Bourouiba, Visualization of sneeze ejecta: steps of fluid fragmentation leading to respiratory droplets. Exp Fluids 57(2), 24 (2016). https://doi.org/10.1007/ s00348-015-2078-4

75. E.Y. Shiu, N.H. Leung, B.J. Cowling, Controversy around airborne versus droplet transmission of respiratory viruses: implication for infection prevention. Curr. Opin. Infect. Dis. 32, 372-379 (2019)

76. X.A. Si, M. Talaat, J. Xi, SARS COV-2 virus-laden droplets coughed from deep lungs: Numerical quantification in a single-path whole respiratory tract geometry. Phys. Fluids 33, 023306 (2021)

77. P. Singh, R.P. Mahajan, G.E. Murty, A.R. Aitkenhead, Relationship of peak flow rate and peak velocity time during voluntarv couzhinc. Br. J. Anaesth. 74(6), 714-716 (1995)

78. J.R. Stokes, G.A. Davies, Viscoelasticity of human whole saliva collected after acid and mechanical stimulation. Biorheology 44(3), 141-160 (2007)

79. R. Stutt, R. Retkute, M. Bradley, C.A. Gilligan, J. Colvin, A modelling framework to assess the likely effectiveness of facemasks in combination with "lock-down" in managing the COVID-19 pandemic. Proc. Math. Phys. Eng. Sci. 476, 20200376 (2020)

80. G.Q. Sun, J.H. Xie, S.H. Huang, Z. Jin, M.T. Li, L. Liu, Transmission dynamics of cholera: Mathematical modeling and control strategies. Commun. Nonlinear Sci. Numer. Simul. 45, 235-244 (2017)

81. G.Q. Sun, S.F. Wang, M.T. Li, L. Li, J. Zhang, W. Zhang, G.L. Feng, Transmission dynamics of COVID19 in Wuhan, China: effects of lockdown and medical resources. Nonlinear Dyn. 101(3), 1981-1993 (2020)

82. B. Tang, X. Wang, Q. Li, N.L. Bragazzi, S. Tang, Y. Xiao, J. Wu, Estimation of the transmission risk of the 2019-nCoV and its implication for public health interventions. J. Clin. Med. 9(2), 462 (2020)

83. J.W. Tang et al., Airflow dynamics of coughing in healthy human volunteers by shadowgraph imaging: an aid to aerosol infection control. PLoS ONE 7(4), e34818 (2012). https://doi.org/10.1371/journal. pone.0034818

84. J.W. Tang, A.D. Nicolle, J. Pantelic, M. Jiang, C. Sekhr, D.K. Cheong, K.W. Tham, Qualitative real-time schlieren and shadowgraph imaging of human exhaled airflows: an aid to aerosol infection control. PLoS ONE 6(6), e21392 (2011) 
85. J.W. Tang et al., Airflow dynamics of human jets: sneezing and breathing - potential sources of infectious aerosols. PLoS ONE 8(4), e59970 (2013). https://doi.org/10.1371/journal.pone.0059970

86. J.W. Tang, T.J. Liebner, B.A. Craven, G.S. Settles, A schlieren optical study of the human cough with and without wearing masks for aerosol infection control. J. R. Soc. Interface 6(Suppl_6), S727-S736 (2009)

87. J.W. Tang, G.S. Settles, Coughing and aerosols. N. Engl. J. Med. 359(15), e19 (2008)

88. G.N.S. To, M.P. Wan, C.Y.H. Chao, L. Fang, A. Melikov, Experimental study of dispersion and deposition of expiratory aerosols in aircraft cabins and impact on infectious disease transmission Aerosol Sci. Technol. 43, 466-485 (2009). https://doi.org/10.1080/02786820902736658

89. C.E. Turner, M.W. Jennison, H.E. Edgerton, Public health applications of high-speed photography. Am. J. Publ. Health Nat. Health 31(4), 319-324 (1941)

90. H. Ueki, Y. Furusawa, K. Iwatsuki-Horimoto, M. Imai, H. Kabata, H. Nishimura, Y. Kawaoka, Effectiveness of Face Masks in Preventing Airborne Transmission of SARS-CoV-2. mSphere 5, e00637-20 (2020)

91. M. VanSciver, S. Miller, J. Hertzberg, Particle image velocimetry of human cough. Aerosol Sci. Technol. 45(3), 415-422 (2011). https://doi.org/10.1080/02786826.2010.542785

92. N. Van Doremalen, T. Bushmaker, D.H. Morris et al., Aerosol and surface stability of sars-cov-2 as compared with sars-cov-1 N. Engl. J. Med. 382, 1564-1567 (2020). https://doi.org/10.1056/NEJMc2004973

93. E. Villermaux, B. Bossa, Single-drop fragmentation determines size distribution of raindrops. Nat. Phys. 5(9), 697-702 (2009)

94. V. Vuorinen, M. Aarnio, M. Alava et al., Modelling aerosol transport and virus exposure with numerical simulations in relation to SARS-CoV-2 transmission by inhalation indoors. Safety (2020). https://doi. org/10.1016/j.ssci.2020.104866

95. M.P. Wan, G.N.S. To, C.Y.H. Chao, L. Fang, A. Melikov, Modeling the fate of expiratory aerosols and the associated infection risk in an aircraft cabin environment Aerosol Sci. Technol. 43, 322-343 (2009). https://doi.org/10.1080/02786820802641461

96. M.X. Wang, S.X.W. Gwee, P.E.Y. Chua, J. Pang, Effectiveness of surgical face masks in reducing acute respiratory infections in non-healthcare settings: a systematic review and meta-analysis. Front. Med. 7, $564280(2020)$

97. X. Wang, E.G. Ferro, G. Zhou, D. Hashimoto, D.L. Bhatt, Association between universal masking in a health care system and SARS-CoV-2 positivity among health care workers. JAMA 324, $703-704$ (2020)

98. J. Wei, Y. Li, Human cough as a two-stage jet and its role in particle transport. PLoS ONE 12(1), e0169235 (2017). https://doi.org/10.1371/journal.pone.0169235

99. W.F. Wells, On air-borne infection: study II. Droplets and droplet nuclei. Am. J. Epidemiol. 20, 611-618 (1934)

100. W.F. Wells, M.W. Wells, Air-borne infection. J. Am. Med. Assoc. 107, 1698-1703 (1936)

101. Wells, W. F. Airborne Contagion and Air Hygiene. An Ecological Study of Droplet Infections. Airborne Contag. Air Hyg. Ecol. Study Droplet Infect. (1955).

102. J. Wei, Y. Li, Human cough as a two-stage jet and its role in particle transport. PLoS ONE 12(1), e0169235 (2017)

103. X. Xie, Y. Li, H. Sun, L. Liu, Exhaled droplets due to talking and coughing. J. R. Soc. Interface 6(suppl_6), S703-S714 (2009). https://doi.org/10.1098/rsif.2009.0388.focus

104. Y. Xing, L. Song, G.Q. Sun, Z. Jin, J. Zhang, Assessing reappearance factors of H7N9 avian influenza in China. Appl. Math. Comput. 309, 192-204 (2017)

105. S. Yang, G.W. Lee, C.M. Chen, C.C. Wu, K.P. Yu, The size and concentration of droplets generated by coughing in human subjects. J. Aerosol Med. 20(4), 484-494 (2007)

106. G. Zayas, M.C. Chiang, E. Wong, F. MacDonald, C.F. Lange, A. Senthilselvan, M. King, Cough aerosol in healthy participants: fundamental knowledge to optimize droplet-spread infectious respiratory disease management. BMC Pulm. Med. 12(1), 1-12 (2012)

107. Y. Zhang, G. Feng, Y. Bi, Y. Cai, Z. Zhang, G. Cao, Distribution of droplet aerosols generated by mouth coughing and nose breathing in an air-conditioned room. Sustain. Cities Soc. 51, 101721 (2019). https:// doi.org/10.1016/j.scs.2019.101721

108. R. Zhang, Y. Li, A.L. Zhang, Y. Wang, M.J. Molina, Identifying airborne transmission as the dominant route for the spread of COVID-19. Proc. Natl. Acad. Sci. 117, 14857-14863 (2020)

109. B. Zhao, Z. Zhang, X. Li, Numerical study of the transport of droplets or particles generated by respiratory system indoors. Build. Environ. 40(8), 1032-1039 (2005)

110. B. Zhao, C. Chen, Z. Tan, Modeling of ultrafine particle dispersion in indoor environments with an improved drift flux model. J. Aerosol Sci. 40, 29-43 (2009)

111. S. Zhu, S. Kato, J.H. Yang, Study on transport characteristics of saliva droplets produced by coughing in a calm indoor environment. Build. Environ. 41(12), 1691-1702 (2006) 
112. N. Zhu, D. Zhang, W. Wang, X. Li, B. Yang, J. Song, China Novel Coronavirus Investigating and Research Team, A novel coronavirus from patients with pneumonia in china, 2019. N. Engl. J. Med. 382(8), 727-733 (2020). https://doi.org/10.1056/nejmoa2001017 